\title{
Direct Orange 26 Dye Environmental Degradation: Experimental Studies (UV, Mass and Thermal) in Comparison With Computational Exploration Hydrogen Bonding Analysis of TD-DFT Calculations
}

\section{Zahraa A. M. Abo-Ayad}

Health ministry Egypt

Mohamed A. Zayed ( $\square$ mazayed429@yahoo.com )

Chemistry Department, Faculty of Science, Cairo University https://orcid.org/0000-0003-2425-6329

Mahmoud A Noamaan

Mathematic department, Faculty of Science, Cairo Universit

\section{Research Article}

Keywords: D026 dye degradation, Spectroscopic data, Thermal Analyses, DFT-TD-DFT, NTOs, Bader's atoms-in-molecule $(\mathrm{AIM})$, transfer length $(\Delta \mathrm{r})$-ground state $(\Delta \mathrm{CT})$

Posted Date: September 13th, 2021

DOl: https://doi.org/10.21203/rs.3.rs-776125/v1

License: (c) (i) This work is licensed under a Creative Commons Attribution 4.0 International License.

Read Full License 


\section{Abstract}

The importance of this study stems from, it concentrates on new approach applying both practical and theoretical aspects to study structure stability of Direct orange dye 26 (D026) as an important dye widely used for dyeing of cotton or viscose for red orange direct printing. The stable dyes are so difficult to remove, decolorized and/ or degrade, in pure solution or in wastewater samples, without using powerful removal environmental techniques electrochemical oxidations suggest and efficiently used in our Lab. Therefore, it is very important to compare between practical thermal and mass results as efficient techniques in studying dye stability, in comparison with theoretical results using Gaussian program for structural stability identification of D026 dye, via careful inspection of various phenomena detected in its two symmetrical arms around urea center. Direct orange dye 26 (D026) structure has been studied applying both practical spectroscopic and theoretical investigations. DFT-B3LYP/6-311++G(d,p) calculations and the electronic vibrational properties are performed to investigate its structure stability and consequently its degradation and removal from its environmental media. Correlation is found between experimental and calculated data. An intra-molecular hydrogen bonding interaction had been detected and characterized in dye skeleton. The hydrogen bonding present in the dye structure affecting its vibrational properties had been discussed. Natural population analysis like HOMO and LUMO and high quality molecular electrostatic potential plots along with various electronics had been presented at the same level of theory. Chemical reactivity descriptors from conceptual density functional theory point of view, structure activity relationship descriptor were obtained. The experimental UV/Visible, FT-IR, mass and GC-mass spectral data of the dye D026 (D1) had been presented. These data had been supported by TD-DFT calculations to simulate the experimental spectra with computing the natural transition orbitals (NTO) and the orbital composition. The variation of charge transfer length $(\Delta r)$ and variation in its dipole moment with respect to ground state $\left(\Delta \mathrm{m}_{\mathrm{CT}}\right)$ had been computed in order to study the charge redistribution due to the excitations. Actually there is a problem that, degradation of this dye in wastewater by different techniques leads to various unknown fragments but on using theoretical possibilities it can be expected what happened in practical work.

\section{Introduction}

Direct dyes are those of more than one azo group, phthalocyanine, stilbene or oxazine containing compounds. In the color index, considered the direct dyes form the second largest dye class with respect to the amount of different dyes [1]. D026 is reddish orange to light yellowish red color textile dye. Therefore; D026 can be used for dyeing cotton or viscose for red orange direct printing. It also can be used for silk, wool, polyvinyl alcohol, polyamide fiber fabric and pulp dyeing [2-5]. The commercial dyestuff DO26 has a general formula $\mathrm{C}_{33} \mathrm{H}_{22} \mathrm{~N}_{6} \mathrm{Na}_{2} \mathrm{O}_{9} \mathrm{~S}_{2}$ of M.Wt. $=756.67 \mathrm{~g} \mathrm{~mol}^{-1}$ [6].

Pollution of water by dyes is a serious problem in developed countries. Approximately, $1-10 \%$ or more of dyes are discharged into waste streams without treatment by the textile industry worldwide. The effluents from the textile dyeing industry contain many organic pollutants and are a serious environmental hazard because of their lasting color, high chemical oxygen demand, and non-biodegradability [6]. Therefore, the 
understanding spectroscopic vibrational, electronic structural, tautomerism, electronic excitation, chemical reactivity and hydrogen bonding analysis of D026 by applying both practical and theoretical techniques are very important factors in studying its structural stability relationship and main target in the present research in removal of this dye from wastewater as great challenge.

DFT has been considered as an efficient tool for dying structural stability and vibrational properties of biomolecules [7, 8]. DFT when incorporated by proper functional exchange-correlation; it provides sufficient confidence about the results. For computational low cost B3LYP hybrid functions became popular because of its accuracy; it is combined with Becke three parameters exchanges and with Lee, Yang and Parr's correlation. The B3LYP function combined with 6-311++G(d,p) basis set were used to calculate structure and vibrational properties of direct dye D026 molecule. On comparison of FTIR and UV-Visible spectra of D026 are shown good correlations between experimental and computational data. Most molecular calculated properties were electronic and thermodynamic. It also involved estimation of chemical reactivity and reaction paths. In DFT also Natural population analysis (NPA), HOMO, LUMO and molecular electrostatic potential (MESP) surfaces were calculated. They were used to discuss resulting intra-molecular charge transfers and electron density distribution as main functions controlling the studied dye stability.

Hydrogen bonding plays a pivotal role in determining the structures stability and properties of biomolecules [9]. The study of hydrogen bonding phenomena had been successfully studied applying Bader's atoms-in-molecule (AIM) theory [10]. The nature and strength of various types of hydrogenbonded interactions had been efficiently described by the AIM theory. The reliability and stability in the values of AIM parameters have been studied and it was found that they are almost independent of basis set on the use of functional B3LYP in DFT [11]. However, it has been noticed that B3LYP function estimates weak intramolecular interactions as well as charge transfer effects [11-13].

\section{Experimental}

\subsection{Chemicals and procedures}

D026 was purchased from Anil Dyes and Chemicals Industries (India). A Perkin Elmer lambda 4B spectrophotometer had been used for measurements of the UV/Visible absorption spectra of the dye using $1.0 \mathrm{~cm}$ fused quartz cells at room temperature. A stock solution $(400 \mathrm{mg} / \mathrm{L})$ of Direct orange textile dye with the M.Wt. $=756.67 \mathrm{~g} \mathrm{~mol}^{-1}$ was prepared by dissolving $200 \mathrm{mg}$ in small amount of distilled water, then the solution was completed to $500 \mathrm{~mL}$ measuring flask. Dilute aqueous solutions of $(1.057 \mathrm{x}$ $10^{-3} \mathrm{M}$ ) D026 were used for most measurements in $10 \mathrm{~mL}$ measuring flask. The FT-IR spectra of $\mathrm{KBr}$ discs containing D1 had been measured at wavenumber region $4000-400 \mathrm{~cm}^{-1}$ using FTIR 4100, JASCO spectrophotometer. Thermal analyses (TGA, DTG, and DTA) were carried out in dynamic nitrogen atmosphere $\left(20 \mathrm{~mL} \mathrm{~min}{ }^{-1}\right)$ with a heating rate of $10^{\circ} \mathrm{C} \mathrm{min}^{-1}$ using Shimadzu system of DTG-60H thermal analyzers. Electron ionization (EI) mass spectrum (MS) for D026 dye was obtained using Thermo Finnegan TRACE DSQ quadruple mass spectrometer with electron multiplier detector equipped 
with GCMS data system. The direct probe (DP) for solid material was used in this study. The sample was put into a glass sample micro-vial, by a needle $(\approx 1 \mu \mathrm{g}$ max $)$, the vial installed on the tip of the DP containing heating cable and inserted into the evacuated ion source. The sample was ionized by an electron beam emitted from the filament, the generated ions being effectively introduced into the analyzer by the focusing and extractor lenses system. The mass spectrum was continuously scanned and the obtained spectra were stored. El mass spectra were obtained at ionizing energy value of 70 and $15 \mathrm{eV}$, ionization current of $60 \mu \mathrm{A}$ and vacuum is better than $10-6$ torr.

(Agilent Technologies Agilent 6890N GC/MS System) coupled with a mass detector (5977B MSD Network Mass Selective Detector) equipped with 70-eV electron impact (EI) mode was used for analyzing residual organic matters that extracted from treated solution For this experiment, a $30 \mathrm{~cm}$ column with an internal diameter of $0.25 \mathrm{~mm}$ was used. The stationary phase was actually bonded to the interior of the glass capillary, eliminating the need for packing a solid support in the column. The mass spectrometer and GC are controlled by Mass Hunter Acquisition software. Most instrumental Analyses were performed in Microanalytical Center Cairo University.

\subsection{Electrochemical Oxidation of D026 dye and GC-mass identification of its degradation products}

The main electrochemical degradation process was investigated in cylindrical glass cell with electrolyte volume of $50 \mathrm{~mL}$. The electrolyte was prepared from Direct orange 26 (D026) dye, using graphite electrodes at optimum conditions $6 \mathrm{~g} / \mathrm{L} \mathrm{NaCl}$ as electrolyte and $\mathrm{pH}=2$ at current intensity $40 \mathrm{~mA}$. To enhance the mass transport and to maintain a uniform concentration of the electrolyte, the reactor solution was constantly stirred at $100 \mathrm{rpm}$ using a magnetic stirrer. The electrochemical treatment was operated for 30 min using graphite electrodes as anode and as cathode. Both anode and cathode were fixed at same distance of $2 \mathrm{~cm}$ both sides of the cell and immersed in the electrolyte.

Gas-chromatography that coupled with mass spectrometry (GC-MS) was used for the identification products resulting from electro-oxidation of D026 dye. Samples of the D026 dye solutions after the electro-oxidation, were collected, extracted using dichloromethane $[14,15]$ and effluent with $n$-hexane (1 $\mathrm{mL}$ ). Effluents were collected and analyzed in GC/MS system. Analysts fragments were separated in GC using an Agilent HP-5ms Ultra Inert capillary column (30.0 m* $0.25 \mathrm{~mm} * 0.25 \mu \mathrm{m})$. The temperature program began at $50^{\circ} \mathrm{C}$ and increased at the rate of $8^{\circ} \mathrm{C} \mathrm{min}^{-1}$ up to $250^{\circ} \mathrm{C}$ with holding time of $3 \mathrm{~min}$ for each increment. Helium was used as carrier gas with a flow rate of $1.0844 \mathrm{~mL} \mathrm{~min}{ }^{\otimes 1}$. Detection in MS followed the separation. A sample of $1 \mu \mathrm{L}$ volume was injected in splitless mode.

\subsection{Computational details}

The Gaussian 09W software package [16] had been used for theoretical calculations. The molecular geometry for the studied compound had been fully optimized using density functional theory B3LYP method by using 6-311 ++G(d,p) basis set $[17,18]$. Where (B3) [19-21] stands for Becke's three parameters combined with gradient-corrected functions of Lee, Yang and Parr (LYP) [22], During geometry 
optimization no symmetry constrains had been applied $[23,24]$. The choice of basis set $6-311++G(d, p)$ is mainly due to its flexibility, accuracy, consistent and better performance when using diffused Gaussian type triple- $\zeta$ potential $[25,26]$. The vibrational frequencies have been determined and checked and proved that, all structures correspond to true minima of the potential energy surface at the same level of theory.

The Gaussian 09W software package has been used for NBO calculations using NBO 3.1 program implemented in the same program. The Gauss View version 5.0.9 [27] involving Chemcraft version 1.6 package [28] had been used throughout this work to optimize the structures of tested compounds. In addition, the Multiwfn v3.8 software program [29] has been used to compute quantum chemical descriptors from point of view of conceptual density functional theory (CDFT). The Multiwfn v3.8 software program [29] has been also used for Atom in molecule (AIM) analysis. The vertical linearresponse TD-DFT approximation [30] has been also used for calculation of the first 80 low-lying excited states. The Polarizable Continuum Model (PCM) [31,32] has been included in all steps of a modeling of bulk solvent effects.

Computing the natural transition orbitals (NTO) [33] have been used in analyzing the electronic properties of tested molecules excited states. The molecular fragments to occupy (occ.NTOs) and virtual natural transition orbitals (virt NTOs) had been performed by the orbital composition analysis taking into consideration the Hirshfld percent contributions. The Multi wave function v3.8 software program [29] had been used to estimate the electronic transitions between the ground state $\left(\mathrm{S}_{0}\right)$ and the low-lying singlet excited states $\left(S_{n}\right)$. In order to study the charge redistribution due to the excitations in tested molecules; the variation in dipole moment with respect to ground state $(\Delta \mu \mathrm{CT})$ [29] and the charge transfer length $(\Delta r)[34,35]$ were computed.

The VMD 1.9 program [35] has been used for rendering the color mapped isosurface graphs of electrostatic potential (ESP) of the ground states of the studied dye; based on the data outputted by Multiwfn program. The VibAnalysis code [36, 37] with corresponding to VEDA program [38] has been used for calculation of the potential energy distribution (PED) for various vibrational normal modes of the studied D026 dye (D1).

\section{Results And Discussions}

\subsection{Thermal Analyses of TGA and DTA analyses of D026 dye powder:}

The thermal analyses data of D026 textile dye is shown in Fig. 1.

Thermal Analyses data of Direct Orange 26 (DO26) refer to its stability when heated from 25 to $1000^{\circ} \mathrm{C}$ with practical total weight loss of $93.24 \%$. Figure (1-a) refers to its TGA, which shows three weight losses. The first loss of practical $\%=3.2 \%$ starts at $31.40^{\circ} \mathrm{C}$ to end at $334.76{ }^{\circ} \mathrm{C}$; which can be assigned to loss of the water of crystallization and coordinated water. 
It appears in DTG (Fig. 1-b) as one loss exactly at $59.60^{\circ} \mathrm{C}$. This loss appears as two exothermic peaks appear in DTA curve (Fig. 1-C) in temperature range from 113 to $400^{\circ} \mathrm{C}$ exactly at 113.74 , and $324.99{ }^{\circ} \mathrm{C}$. Therefore; the first loss seems to occur in two consecutive steps. The second weight loss occurs in temperature range from 334.76 to $644.64{ }^{\circ} \mathrm{C}$ of practical weight loss $\%=3.83 \%$ (Fig. 1-a); which may be due to the release of $\mathrm{N}_{2}$ gas (estimated weight loss \% = 3.70 \%). It appears in DTG (Fig. 1-b) as two losses exactly at 438.27 and $640.76^{\circ} \mathrm{C}$. This loss appears in DTA (Fig. 1-C) at $636.23{ }^{\circ} \mathrm{C}$ as small endothermic peak. It may be attributed to the degradation of the azo bonds $(-\mathrm{N}=\mathrm{N}-)$; which links between naphthalene and benzene rings. The third weight loss appears that, D026 dye decomposed mainly $\left(\mathrm{C}_{33} \mathrm{H}_{22} \mathrm{~N}_{2} \mathrm{O}_{8} \mathrm{~S}_{2}\right)$ within the temperature range from 644.64 to $1000.42{ }^{\circ} \mathrm{C}$ with practical weight loss $\%=$ $86.21 \%$ (estimated weight loss \% $=84.32 \%$ ). Appears as a sharp large peak exactly at $967.11^{\circ} \mathrm{C}$ in DTG (Fig. 1-b), and as small endothermic peak at $808.54^{\circ} \mathrm{C}$ in DTA (Fig. 1-c). The residual mass which represent $6.76 \%$ may be referred to sodium oxide $\left(\mathrm{Na}_{2} \mathrm{O}\right.$ with estimated weight $\left.\%=8.19 \%\right)$. The thermal degradation of the dye at temperature range up to $1000{ }^{\circ} \mathrm{C}$ refer to its very high stability and it required very efficient degradation tools like chemical or electrochemical oxidation to be removed from environment wastewater which is actual performed in another paper. Most of these thermal fragments are correlated to most of fragment ions appeared in mass spectra of pure powder dye and of GC-mass of dye of electro-oxidation of degradation products fragment ions.

\subsection{Mass spectra of powder D026 dye}

Mass spectral fragmentation of D026 textile dye molecule using El-MS at $70 \mathrm{eV}$ is shown if Fig. 2.

These results (Fig. 2) show two $\mathrm{m} / \mathrm{z}$ values first one at $\mathrm{m} / \mathrm{z}=756$; which is mainly related to the disodium salt of the dye of molecular formula: $\mathrm{C}_{33} \mathrm{H}_{22} \mathrm{~N}_{6} \mathrm{Na}_{2} \mathrm{O}_{9} \mathrm{~S}_{2}$ of mol mass 756.67 and another peak at $\mathrm{m} / \mathrm{z}=$ 734 , which is mainly attributed to molecular ion of the dye without sodium of general formula $\mathrm{C}_{33} \mathrm{H}_{24} \mathrm{~N}_{6} \mathrm{O}_{9} \mathrm{~S}_{2}{ }^{+}$and mol mass $=735.7 \mathrm{~g} / \mathrm{mol}$. These results and its fragmentation refer to its pure form and the possibility to decompose to several fragment ions on mass measurements. Most of these molecular and fragment ions are appeared like those appear at $\mathrm{m} /=57,71,85,105$ and 111 in thermal degradation of dye in its powder form. Some of these fragment ions are appeared in GC-mass spectra of electro-oxidized dye products.

\subsection{Spectral and electrochemical oxidation results}

UV/Vis spectra relative to D026 dye and its actual textile wastewater sample treated by electrochemical oxidation/reduction reaction in one cell using graphite electrodes as both anode and cathode at different time intervals (Fig. S1) refer to; after 4 min of electrolysis under chosen optimum conditions with $49.84 \%$ decolourization with high decomposition of the azo group. Also it shows $83.22 \%$ decolourization of D026 actual sample after 12 min of electrochemical oxidation/reduction. This decolorization is lower than the decolorization of the dye dissolved in distilled water $97.77 \%$. Less decolorization attributed to field additives used to coat the dye to textiles by physical and especially chemical reaction which gives more stability for the dye in its medium. The degradation and color removal of D026 dye occurred only in 
the presence of chloride. Thus, the decolorization of the dye is due to its main reaction with the generated chlorine/hypochlorite; in which the chlorine/hypochlorite oxidizes the dye and it is then reduced to chloride ion [39]; such as $\mathrm{DO} 26+\mathrm{OCl}^{\square} \rightarrow \mathrm{CO}_{2}+\mathrm{H}_{2} \mathrm{O}+\mathrm{Cl}^{\square}+$ by-products. On the other hand, in cathodic compartment the reaction assumed to take place as follows: $2 \mathrm{H}_{2} \mathrm{O}+2 \mathrm{e}^{\square} \rightarrow \mathrm{H}_{2}+2^{\square} \mathrm{OH}$ and so; the dye chromogen $(\mathrm{N}=\mathrm{N})$ groups were reduced to give $\approx 30 \%$ with no significant $\mathrm{COD}$ reduction.

The GC-MS results show that, at a retention time of $14.21 \mathrm{~min}$; benzene diazonium with molecular ion peak with m/z 105 resulted from the main degradation of D026 dye (Fig S2). The benzene fragment with $\mathrm{m} / \mathrm{z} 77$ at retention time 10.445 min has been obtained directly by oxidation from benzene diazonium [40]. A non-hydroxylated fragment, dichlorobenzene, peak with $\mathrm{m} / \mathrm{z} 148$ at retention time $16.53 \mathrm{~min}$ and mono-hydroxylated fragment, pentachlorophenol, peak with $\mathrm{m} / \mathrm{z} 267$ at retention time 31.06 min were obtain from the progressive chlorination of simple by-products as benzene. The ion peak having retention time 16.20 min was identified as a-naphthol with $\mathrm{m} / \mathrm{z} 144$ resulted from the further electrochemical oxidation of the other identified intermediates, 1,2,6-trihydroxy naphthalene sulfonate with $\mathrm{m} / \mathrm{z}=255.8$ and 3-amino-7-(carboxyamino)naphthalene-2-sulfonic acid with $\mathrm{m} / \mathrm{z}=281$ at retention time 27.75 and $33.33 \mathrm{~min}$, respectively. So; the cleavage of the D026 dye may take place symmetrically or asymmetrically. The main degradation of D026 dye in this study occurred asymmetrically by breakage the bond between the nitrogen of azo group and the carbon of 2-hydroxy-3-naphthalene- sulfonate ring. To assess the practical environmental work, it seems reasonable to support the above data by correlation with theoretical calculation and give main reasons of its high stability, which required more powerful environmental removal tools like thermal, chemical and/ or electrochemical oxidation.

\subsection{Density functional theory (DFT) studies}

The molecular electrostatic potential maps, bond lengths, bond angles and dihedral angles as the optimized geometrical parameters were calculated. Also natural charges, natural population analysis, reactivity descriptors, and energetic were computed. All of these calculated parameters were analyzed for the studied dye D1 both in water and gas phases of the ground state and compared with the practical elemental analyses and spectroscopic data.

\subsubsection{Optimized structure and hydrogen bonding of D1}

Table (1) and Fig. 3 present the computed parameters of D1 in this work; such as optimized geometry, numbering system, vector of the dipole moment, bond lengths, bond angles and dihedral angles.

Figure 3. The optimized geometry of D026 dye (D1) compounds using B3LYP/6-311 ++G(d,p) level of theory, the numbering system and vector of dipole moment.

The data in Table 1 and Fig. 3 refer to the maximum C-C bond length (among others) of $1.454 \AA$ in naphthalene ring system that in good agreement with the reported value of $1.42 \AA$ [41, 42]. The bond angle C37-C36-C27 calculated is found to be $119.75 \AA$; it shows excellent agreement with the reported value of $119.4 \AA[41,42]$. The dye D1 is considered urea derivative fragment in which the urea calculated 
bonds $\mathrm{C} 1-02, \mathrm{C} 1-\mathrm{N} 3$ and $\mathrm{C} 1-\mathrm{N} 4$ give values of $1.223,1.393$ and $1.377 \AA$. The corresponding practical values of these bonds in D1 are found to be 1.245, 1.345and 1.329 $\AA$. The selected angles in the tested dye $02 \mathrm{C} 1 \mathrm{~N} 3$ and $\mathrm{N} 3 \mathrm{C} 1 \mathrm{~N} 4$ are found to be of the values $119.22^{\circ}$ and $115.86^{\circ}$; while the respective angles in urea are found to be $120.34^{\circ}$ and $118.29^{\circ}[41,42]$. Thus, bonds are affected by the presence of two arms of D1 (Fig. 3) with sequence (right arm: C7 to H39) and (left arm: C40 to H58).

The computed values of dihedral angles around central urea derivatives are represented in Table 1 . They show that, the angle $\mathrm{N} 4 \mathrm{C} 1 \mathrm{~N} 3 \mathrm{C} 7$ is of $10.9^{\circ}$ degree right arm out of plane and the angle $02 \mathrm{C} 1 \mathrm{~N} 4 \mathrm{C} 40$ is of $5.74^{\circ}$ and degree left arm out of plane. This indicates that the carbon derivative is almost in the same molecular plane of urea. Also, atoms in angles C8C9C10C11, C11C12C13025, C11C12N26N27, N26N27C28C29, N26N27C28C33 of the values $180,180,179.9,-0.3,179.76$ degree; refer to the planarity of right arm component due to symmetry of the molecular structure. The left arm one is almost planar; which represented by angles N60C61C62C63, C41C42C47C48, C44C45C46058 of values 180, 0.0 and 180.0 degrees respectively.

AIM theory calculations refer to the presence of hydrogen bonds in the skeleton of D1; that follows Koch and Popelier criterion [43]. The hydrogen bonding requires the existence of bond critical point (BCP) for the 'proton donor $(\mathrm{H})$ and acceptor $(\mathrm{A})^{\prime}$ ' contact. Applying this theory to D026 it shows a lot of intramolecular hydrogen bonding interaction $025-\mathrm{H} 39,058-\mathrm{H} 72, \mathrm{O} 2-\mathrm{H} 50,023 \mathrm{H} 20,074-\mathrm{H} 53$ in diazo-carbonyl fragment in two arms. The application of this theory [43] actually required the value of electron density (q) in the range $0.002-0.040$ a.u. and corresponding Laplacian $\left(\nabla^{2} \rho\right)$ should be $0.024-0.139$ a.u. These parameters have been calculated for the studied $\mathrm{D} 1$ at BCP with sequence $025 \ldots \mathrm{H} 39,058 \ldots \mathrm{H} 72,02 \ldots \mathrm{H} 50$, $023 \ldots \mathrm{H} 20,074 \ldots \mathrm{H} 53$ along with geometrical parameters of $\mathrm{H}$-bonds and the data obtained are listed in Table 2.

\section{Table 2. The calculated selected geometrical parameters (a.u) using B3lyp/6-311 ++ G (d,p) level of theory, bond length $(\AA)$ and binding energy ( $\mathrm{kcal} / \mathrm{mol})$ of D026 dye (D1).}

There are three types of H-bonds have been detected in the basis of D1 topology [44] via calculated parameters. The characterization has been followed Rozas et al. [44] demands; at BCP in which; $\nabla^{2} \rho$ andHcript $>$ for strong $\mathrm{H}$-bonding of covalent character. It also should be $\nabla^{2} \rho>0$ And $\mathrm{H}<0$ for medium $\mathrm{H}$-bond of partially covalent nature. Alternatively it should be $\nabla^{2} \rho>0$ and $\mathrm{H}>0$ for weak $\mathrm{H}$-bond. From the presented data in Table 2 it is clear that; Laplacian of charge density is positive for all BCP, $\nabla^{2} \rho=0.15,0.15,0.066,0.061,0.062$ and 0.047 . Also the energy density $\mathrm{H}<0$ for the first two $\mathrm{N} 27 \mathrm{H} 39 \ldots \mathrm{O} 25$ and $\mathrm{N} 60 \mathrm{H} 72 \ldots .058$ and others is $\mathrm{H}>0$ suggesting the interaction to be medium $\mathrm{H}$-bond of partially covalent nature in $\mathrm{N} 27 \mathrm{H} 39 \ldots . .025$ and $\mathrm{N} 60 \mathrm{H} 72 \ldots . .058$ and weak in nature for all other BCP. The value of $\nabla^{2} \rho$ is found to be negative and small in magnitude for strong covalent interactions, as in [Mn(III) porphyrin]Cl-trimethoprim complex ( $\nabla^{2} \rho=-0.0786$ a.u.) [45]; and as in bis-dithiazolyl dimers [46]. By using $E_{i n t}=(V)$ at BCP as proposed by Espinosa et al [47]; the energy of interactions occur in tested dye has been theoretically calculated. The estimated interaction energy values of hydrogen bonding in 
the given dye for bonds $025 \ldots \mathrm{H} 39,058 \ldots \mathrm{H} 72,02 \ldots \mathrm{H} 50,023 \ldots \mathrm{H} 20,074 \ldots \mathrm{H} 53$ are found to be -12.36 , $-12.41,-3.8,-3.53$ and $-3.57 \mathrm{kcal} / \mathrm{mol}$, respectively. These data indicate the medium $\mathrm{H}$-bond interactions for $\mathrm{N} 27 \mathrm{H} 39 . . .025$ and $\mathrm{N} 60 \mathrm{H} 72 \ldots . .058$ bonds and other bond are of week interaction [48]. The binding energy more accurate values have been obtained by applying another prediction equation [49] and the found values for bonds $025 \ldots \mathrm{H} 39,058 \ldots \mathrm{H} 72,02 \ldots \mathrm{H} 50,023 \ldots \mathrm{H} 20,074 \ldots \mathrm{H} 53$ are found to be $-8.78,-8.8$, $-3.26,-2.73$ and $-2.8 \mathrm{kcal} / \mathrm{mol}$ respectively.

\subsubsection{The tautomeric relative stability of D1}

From the above calculations and practical work data; the depicted three different tautomeric forms of the D026 (D1) dye (Fig. S3) are di-keto form ( $A, C_{13}=\mathrm{O}_{25}, \mathrm{C}_{46}=\mathrm{O}_{58}$ ), keto-enol forms (B and C) and di-enol forms (D and E) and corresponding four transition states (TS) (F-I) are suggested. The proposed relative potential energy surface diagram for different three tautomeric forms and TS of D1 (A-I), are represented in Fig. 4.

The data in Fig. 4 give great benefit in explaining structural behavior of the studied dye and its stability. The DFT calculations reveal that the stability order of different forms $(A-E)$ of the D026 dye is $A>B>C>$ $D=E$ as given by their calculated relative energy values of $0.0,3.24,3.29,6.54 \mathrm{Kcal} / \mathrm{mol}$ respectively. These data refer to the di-keto form of D1 is the most stable tautomer in the gas phase. This conclusion is confirmed by the calculated energy values of corresponding four transition states (TS) (F-I) with respect to $A$ with $5.6,5.65,8.9 \mathrm{Kcal} / \mathrm{mol}$ respectively; which have stability order of $F<G<H=I$. The stability of the di-keto form (A) relative to the keto-enol (B), enol-keto (C) and the di-enol (D) forms may be attributed to the increasing in the strain effects within the moiety of these forms. There is a transfer of the single proton between the oxygen atoms ( 025 or 058 ). On the other hand proton is moved in opposite directions relative to the nitrogen atoms $\left(\mathrm{N}_{27}\right.$ or $\mathrm{N}_{60}$ ) (forms $B$ and $\mathrm{C}$ ). It is also noticed that; form $\mathrm{C}$ is less stable than form $B$; which may be attributed to the electrostatic attraction between the proton and the oxygen atom. The stability of $\mathbf{A}$ (the di-keto form) may be attributed to the planarity of right and left part arms for central carbonyl group $\mathrm{C} 1=02$.

\subsubsection{Normal mode analysis and FT-IR of D1}

The vibrational normal mode analysis confirm that; the most of the calculated frequencies of the optimized geometry of D1 (Fig. 4) are found to be real. Consequently; the D1 optimized geometry corresponds to a true minimum energy in the PES. The obtained frequency values applying the present theoretical model are scaled with a factor of 0.96 [50] to avoid errors due to neglect of inharmonic terms. All the vibrational modes are properly assigned applying the basis of PED. By using free VibAnalysis code $[46,47]$ with corresponding to VEDA program [48]; the various vibrational normal modes have been calculated. The calculated FTIR frequency intensities and assignments listed in Table 3; are selected in normal modes up to $400 \mathrm{~cm}^{-1}$. All normal modes with all details up to $400 \mathrm{~cm}^{-1}$ are presented in Table S1 as supplementary information. 
Table 3. Selected vibrational normal modes of analysis, including FT-IR values, for D1 obtained using B3LYP/6-311 + G (d,p) level of theory

Figure 5 presents simulated FT-IR spectra at 400 to $4000 \mathrm{~cm}^{-1}$ for D026 in comparison with experimental results. The D026 (D1) has two similar arms for the urea derivatives. Each arm is substituted naphthalene and benzene ring linked by diazonium fragment $(=\mathrm{N}-\mathrm{NH}-)$. The $\mathrm{N}-\mathrm{H}$ stretching frequencies of the rings are calculated and found to be in the range $3,473-3,133 \mathrm{~cm}^{-1}$; which is in good agreement with the found values in literature [51] of 3,200 and $3,500 \mathrm{~cm}^{-1}$ with strong or medium intensities.

$\mathrm{N}-\mathrm{H}$ stretching vibration with a PED of almost $90-100 \%$ is calculated at $3,473,3,450,3,1383,133 \mathrm{~cm}^{-1}$ and presented in Table 3. The FT-IR practical value corresponding to this band is found to be $3,466 \mathrm{~cm}^{-1}$. However, the $\mathrm{NH}$ group in acetyl-hydrazine molecule $\left(\mathrm{CH}_{3}-\mathrm{CO}-\mathrm{NH}-\mathrm{NH}_{2}\right)$, is detected at $3,445 \mathrm{~cm}^{-1}$ and confirmed by the calculated one found at $3,640 \mathrm{~cm}^{-1}$ by DFT [52]. The $\mathrm{N}-\mathrm{H}$ stretching band is apparently shifted due to hydrogen bonding with oxygen 025 or 058 attached to naphthalene ring. The intermolecular hydrogen bonding in D1 is stronger than intra-molecular $\mathrm{H}$-bonding as indicated by difference in calculated and experimental frequencies of the same dye indicates that.

The rings $\mathrm{C}-\mathrm{H}$ stretching frequencies at the wavenumber range $3,117-3,024 \mathrm{~cm}^{-1}$ have been calculated. The $\mathrm{C}-\mathrm{H}$ stretching of $\mathrm{C} 49 \mathrm{H} 50$ group near to the $\mathrm{C}=\mathrm{O}$ of central urea has been detected at $3,086 \mathrm{~cm}^{-1}$; which were found to be at 3,000 and $3,100 \mathrm{~cm}^{-1}$ with medium intensities in the published work [51]. The calculated $\mathrm{C}=\mathrm{C}$ stretching vibrations and its mixing with other modes of naphthalene rings are found in lower region at frequency values of 1,574 and $1,559 \mathrm{~cm}^{-1}$ respectively. These theoretically calculated values are also correlated with that reported in literature [51] in which strong absorption band of naphthalene right arm has been detected at $1,571 \mathrm{~cm}^{-1}$ and falling range of $1,600-1,500 \mathrm{~cm}^{-1}$.

The $\mathrm{C}-\mathrm{H}$ bending of ring systems frequencies in plane and out of plane are calculated and found to be ascertained with $\mathrm{C}-\mathrm{C}$ stretching region. The calculated $\mathrm{C}-\mathrm{H}$ vibrational mode of strong intensity for naphthalene ring is found to be at $1,120 \mathrm{~cm}^{-1}$. The naphthalene ring torsion modes are always found in even lower frequency region [51].

The $\mathrm{CH}_{2}$ stretching vibrations of weak intensities in the dye skeleton are detected at 2,954 and 2,907 $\mathrm{cm}^{-}$ 1 . The $\mathrm{CH}_{2}$ bending vibration has been detected at $1,464 \mathrm{~cm}^{-1}$. The $\mathrm{C}-\mathrm{H}$ lying between $\mathrm{N} 14$ and R3 stretching vibration has been practically detected as strong intensity band at $2,904 \mathrm{~cm}^{-1}$. The calculated $\mathrm{C}=0$ stretching band has been theoretically calculated at $1,625 \mathrm{~cm}^{-1}$; which actually fit the practically detected in FTIR value of D1 at 1,638 $\mathrm{cm}^{-1}$. These data are found to be in good correlation with the $C=0$ stretching as a very strong band in the region $1,680-1,640 \mathrm{~cm}^{-1}$ previously reported elsewhere [51]. The $\mathrm{C}-\mathrm{N}$ and $\mathrm{C}=\mathrm{N}$ stretching vibrations coupled with $\mathrm{N}-\mathrm{H}$ scissoring and $\mathrm{CCN}$ and $\mathrm{HNN}$ twisting vibrations respectively in acetyl-hydrazine molecule $\left(\mathrm{CH}_{3}-\mathrm{CO}-\mathrm{NH}-\mathrm{NH}_{2}\right)$ are calculated and found to be 1,499 and $1,428 \mathrm{~cm}^{-1}$. These theoretically calculated values are actually correlated with the practically detected 
values in the wavenumber range at $1,460-1,430 \mathrm{~cm}^{-1}$ in the FT-IR of tested dye. All of these bands of acetyl-hydrazine molecule $\left(\mathrm{CH}_{3}-\mathrm{CO}-\mathrm{NH}-\mathrm{NH}_{2}\right)$ are found to be weak instead of intense band as previously reported [51]. The calculated frequencies belongs to $\mathrm{N}-\mathrm{N}$ stretching has been practically detected at 1,300 and $1,250 \mathrm{~cm}^{-1}$ respectively and bending vibrational deformation modes of the fragment of the same group has been practically detected at 1,352 and $680 \mathrm{~cm}^{-1}$. The theoretically calculated and experimental FT-IR frequencies of D1 at $400-4000 \mathrm{~cm}^{-1}$ are listed in Table 3 and graphically represented in Fig. 6 .

Figure 6 shows a correlation between theoretically calculated and the practically detected frequencies in FT-IR of the dye D026. These data show good and correlation exists with a coefficient of 0.9991 . Such a correlation proved that the DFT/B3LYP scheme of theoretical calculation in the field of spectroscopy is efficiently reproduces the experimental results and can be used for vibrational analysis of biomolecules with a sufficient confidence.

\subsubsection{Natural charges and natural population analysis (NPA) of D1}

The NPA scheme at B3LYP/6-311 ++G(d, p) level had been used in theoretical calculation of atomic charges of the investigated molecule (D1) in gas. These charges are ranged from - 1.001 to 2.299 e and the data obtained are depicted in Table 4. The obtained results proved that; this scheme is more reliable due to its low basis set dependency.

\section{Table 4. Natural charge of selected atoms of D026 dye1 (D1) at B3lyp/6-311 ++G(d,p) level of theory.}

Table 4 shows that; the carbon atoms in the skeleton of the dye D026 are either carrying positive, or negative charges; it depends on its position. The negative charges are concentrated on $023,024,025$, 055,056 and 057 oxygen atoms of $\mathrm{SO}_{3}$ groups. It also has been seen that the charge is around $-1.0 \mathrm{e}$ on each atom. The maximum positive charges on sulpher atoms ( $\mathrm{S} 21$ and $\mathrm{S} 54$ atoms of $\mathrm{SO}_{3}$ groups) have been detected. The nitrogen and oxygen atoms of urea and diazonium fragments are negatively charged and consequently they accept electrons. It is also noticed that; the increase of charge on N27 and N27 as compared to N26 and N59. The decrease in charge on 025 and 058 may be due to electron density transfer from proton donors $\mathrm{N} 27 \mathrm{H} 39$ and $\mathrm{N} 60 \mathrm{H} 72$ to proton acceptors 025 and 058 involved in hydrogen bonding. It is finally noticed that; charges on hydrogen atoms have positive values.

\subsubsection{FMOs analysis}

Table 5 represents Frontier molecular orbitals (FMOs, Figure S4.) data. The represented calculated quantum chemical parameters values are $\mathrm{E}_{\mathrm{HOMO}}, \mathrm{E}_{\mathrm{LUMO}}$, energy gap $\left(\Delta \mathrm{E}_{\text {gap }}\right)$, ionization energy $(\mathrm{I})$, electron affinity (A) and Dipole moment [53-55].

The HOMO (ionization potential I= - EHOMO) energy value usually determines the donating power of electrons of the tested group. Its high value indicates the ease of donating electron to the unoccupied 
orbital of the receptor molecule. The small value of $\mathrm{E}_{\mathrm{LUMO}}$ (electron affinities $\left.\mathrm{A}=-\mathrm{ELUMO}\right)$.means more able to accept electron. The calculated $\mathrm{E}_{\mathrm{HOMO}}$ of the tested dye is found to be $-1.724 \mathrm{eV}$; which is located on the $\mathrm{SO}_{3}$ group system of right arm. On the other hand the $\mathrm{E}_{\mathrm{LUMO}}$, of $\mathrm{DO} 26$ is found to be $0.696 \mathrm{eV}$; which is mainly contributed by all left arm of the dye molecule. The energy $\left(\Delta \mathrm{E}_{\mathrm{gap}}\right)$ between HOMO and LUMO usually described the chemical reactivity of the molecule. In the present study, $\Delta \mathrm{E}_{\text {gap }}$ is found to be $2.42 \mathrm{eV}$; which indicates the high reactivity of the compound in oxidation reduction reaction. Hence the dye is highly reactive and recommends being use in dye sensitized solar cell (DSSC). The ionization potential I and electron affinity $A$ are so important parameters. The determination of these two important parameters allows the calculation of the global reactivity descriptors. The $\mathrm{A}$ and I parameters depend mainly on the one-electron HOMO and LUMO orbital energy values. The molecule of less I value will be the better electron donor; while the molecule of high I value will be the better electron acceptor. From Table 5, it has $1.72 \mathrm{eV}$ value of I and $\mathrm{A}$ is $-0.7 \mathrm{eV}$ and electronegativity is equal $0.51 \mathrm{eV}$. Figure 7 , represents Frontier molecular orbitals of the studied D026 dye compounds (D1).

The data in Fig. 7 show that the dispersion of charge densities of HOMOs and LUMOs indicate charge transfer to naphthalene with azo-phenyl ring (left arm of urea derivatives) from $\mathrm{SO}_{3}$ group of right arm. The dipole moment vector is representing the direction of the electronic charge transfer motion and it equals $10.98 \mathrm{D}$.

\subsubsection{Global reactivity descriptors of $D 1$}

The nature of chemical interactions and chemical reactivity of atoms, ions or molecules are considered important to explain the reactivity of the molecular dye D026 (D1). The CDFT, quantum chemical descriptors like chemical hardness $(\eta)$, electronic chemical potential $(\mu)$, and electronegativity $(\chi)$ are related to the electron number $(N)$ at constant external potential, $v(r)$, respectively [53-55].

Also, Global electrophilicity index $(\omega)$, Global softness $(S)$ and electronegativity $(\chi)$ are computed based on HOMO and LUMO energy values for D1 using B3LYP/ 6-311 ++G(d,p) theory level of calculation [53, 54].

The computed GRD reactivity descriptors of the compound D1 are represented in Table 5. These data have been considered very important to explain the reactivity and stability of studied D026 (D1). D1 has t value of $\eta=1.21 \mathrm{eV}$ of chemical hardness and the softness value $(0.41 \mathrm{eV})$; which indicates softness and chemical reactivity of studied. The results obtained are in good correlation with the find HOMO-LUMO band energy gaps of the synthesized dye. The calculated chemical potential $(\mu)$ value of the studied dye D026 (D1) presented in Table 5 means it has high chemical potential value $(-0.5 \mathrm{eV})$; which refers to the high charge transfer occurs within tested dye.

The electrophilicity index $(\omega)$ is a thermodynamic parameter that measures energy changes in a chemical system saturated by adding electrons. It described the chemical reactivity of a system. The calculated data presented in Table 5 proved that D1 has Electrophilicity index value $(\omega=0.11 \mathrm{eV})$ and the Nueclophilicity index $(\mathrm{N})$ is equals $+2.49 \mathrm{eV}$. These values indicate that the dye favor nucleophilic 
approximate 23 times more than electrophilic. Compound D1 possesses electronegativity (X), value of $0.51 \mathrm{eV}$ as a measure for tendency of molecule to attract electrons means it has high softness values $(0.51 \mathrm{eV})$ and showed high reactivity,

\subsubsection{Local reactivity descriptor of D1}

To understand the chemical reactivity and site selectivity of theoretically tested compounds; it is very important to use the concepts of local and global reactivity descriptors [56,57]. The Fukui function is the first derivative of the electronic density $\rho(r)$ of a system with respect to the number of electrons $(N)$ at a fixed external potential $v(r)$ as defined by Yang and Mortier (1986) [58].

The local descriptors such as electrophilic and nucleophilic Fukui functions had been more clarified by Parr and Yang $[59,60]$. The calculation of Fukui functions is very important to determine the active sites of the D026 dye (D1). It mainly based calculation of the electronic density changes occurred during the molecule reactions. Usually Fukui functions $f^{+}(r), f^{-}(r)$ and $f^{0}(r)$ are essentially calculated in three chemical situations such as electrophilic, nucleophilic and radical attacks [57,60-62]. Where $\mathrm{q}_{\mathrm{k}}(\mathrm{N}), \mathrm{q}_{\mathrm{k}}(\mathrm{N}+1)$ and $\mathrm{q}_{\mathrm{k}}(\mathrm{N}-1)$ are the atomic population on the $k_{t h}$ atom for the neutral molecule, its anionic and cationic species respectively. Chattaraj et al. [63] defined the local quantity called philicity $\omega_{\mathrm{k}}^{\alpha}$ associated with a site $\mathrm{k}$ in a molecule with the assistance of corresponding condensed-to-atom variants of Fukui function, $\mathrm{f}_{\mathrm{k}}^{\alpha}$. Where $\mathrm{a}=+,-$ and 0 correspond to local philic quantities describing nucleophilic, electrophilic and radical attacks, respectively. The highest $\omega_{\mathrm{k}}^{\alpha}$ corresponds to the most electrophilic site in a molecule. Softness $\mathrm{S}_{\mathrm{k}}^{\alpha}$ describe the reactivity of atoms in molecules had been proposed by Lee et al. [22, 63]. Morell and Labbe et al [64] proposed another Dual descriptor $(\Delta \mathrm{f}(\mathrm{r}))$ concerning electrophilic and nucleophilic capacity of a given atomic site in the molecule. Here $\Delta \mathrm{f}(\mathrm{r})$ is the difference between the nucleophilic and electrophilic Fukui function. If $\Delta \mathrm{f}(\mathrm{r})>0$ refers to nucleophilic attack. For $\Delta \mathrm{f}(\mathrm{r}) \mathrm{cript}>$ it is favored for an electrophilic attack. The calculated data using the above equations at the level B3LYP/6-311 ++G $(\mathrm{d}, \mathrm{p})$ for Fukui functions indices, dual descriptor, condensed local softness, local and relative electrophilicity of DO-26 are given in Tables 6-7.

The values of Fukui functionsf ${ }^{-}(r)$ andf $^{+}(r)$ are presented in Table 6.

From these data; it can be stated that the most electrophilic active sites in D026 molecule is located on 055, 056 and 057. Likewise, the active sites susceptible for nucleophilic attacks in the same dye are C7, $\mathrm{C} 9, \mathrm{C} 10, \mathrm{C} 11,025, \mathrm{~N} 26, \mathrm{~N} 27, \mathrm{~N} 59$ and N60. The same conclusion can be reached considering the Dual descriptor $\Delta \mathrm{f}(\mathrm{r})$ regarding electrophilic and nucleophilic attack, also from the philicity indices Table (7).

Table 7. Values of the Condensed local Softnesses (Hartree*e), relative electrophilicity /nucleophilicity (dimensionless) and the Condensed local electrophilicity (ElectroP)/nucleophilicity (NucleoP) index (e*eV) of D026 dye (D1) using B3lyp/6-311 ++G(d,p). 
The characteristic differences between the calculated values of parameters is mainly attributed the redistribution of electron density inside molecules due to high electronegativity of $\mathrm{N}$ and $\mathrm{O}$ atoms in skeleton, also the effect of $-\mathrm{C}=0 . . . \mathrm{HN},-\mathrm{SO}_{3}{ }^{-1}$ groups. The obtained results of the calculated functions are in good agreement with the last population analysis and computed HOMO and LUMO energies.

By using implemented code in Multi wave function v3.8 software program [38]; condensed local softness, local electrophilicity /Nueclophilicity index, and relative electrophilicity/Nueclophilicity have been also calculated for each atom in the studied molecule from CDFT point of view to complete the picture of the studied dye map. The careful inspection of these data revealed that; the dye molecule had the donation and the back-donation processes at their active center $(055,056,057, \mathrm{C} 7, \mathrm{C} 9, \mathrm{C} 10, \mathrm{C} 11,025, \mathrm{~N} 26, \mathrm{~N} 27$, N59 and N60); which is in good agreement with the Fukui functions data. It also agreed well with the obtained frontier orbital results represented in Tables (6-7).

According to these results, one can conclude that the studied dye possess lot of active centers to interact with pocket protein surface, through donating electrons to orbitals and back donation process. The calculated local descriptors data revealed that the theoretical variation efficiencies of the investigative molecules agree well with the available experimental data in the same work.

\subsubsection{Molecular electrostatic potential map (MEP)}

Electrostatic potential (ESP) on molecular van der Waals surfaces have emerged as powerful tools in predicting, interpreting, and rationalizing trends in different areas of chemistry [65] as well as in drug design and molecular biology [66].

ESP-mapped surfaces of the studied compound, D1 are shown in Fig. 8.

\section{Figure 8. ESP-mapped surfaces of the synthesized D026 dye compound (D1)}

Module of Multi wave function program is used for the quantitative molecular surface analysis and it is capable of partitioning the whole van der Waals surface into multiple fragments. It also allows discussion of the characteristics of the ESP distribution of studied dye D1.

The surface of D026 (D1) exhibits large negative value of ESP around the $-\mathrm{SO}_{3}{ }^{-}$groups $(-144.9,-140.3$ $\mathrm{kcal} / \mathrm{mol}) . \mathrm{C} 13=025 \ldots \mathrm{H} 39 \mathrm{~N} 27$ and $\mathrm{C} 46=058 \ldots \mathrm{H} 72 \mathrm{~N} 60(-101.7$ and $102.7 \mathrm{kcal} / \mathrm{mol})$ with spreading the negative charge on different active sites.

It can be asserted on the basis of ESP-mapped, that an electrophile is attracted towards negative region of diazonium and urea center fragment with $-\mathrm{SO}_{3}{ }^{-}$while a nucleophilic attack favors the electropositive region. These values indicate the same results from NPA and local reactivity descriptors analysis mentioned in above sections.

\subsubsection{Electronic absorption spectra}


Direct orange 26 dye (D1) has been synthesized and confirmed to possess antibacterial and application in printing and dyeing [68]. No correlation between experimental and calculated

TDDFT UV/Vis spectra for D026 (D1) had been previously published elsewhere.

To analyze how the UV-Visible spectrum of D1 is varied, the experimental absorption electronic spectra in water solvent and computed are depicted in Fig. 9. The calculated absorption maximum wavelengths $\left(\lambda_{\text {max }}\right)$, electronic excitation energies $(\Delta E)$, and oscillator strengths $(f)$ of D1 in water are given in Table 8 together with the corresponding experimental values.

\section{Table 8: UV spectra parameters that characterized dye D1 in water such as $\left(\lambda_{\max }\right)$, electronic excitation energies $(\Delta E)$, and oscillator strengths $(f)$; both theoretical and experimental data}

These data show six absorption bands with maxima at $511 \mathrm{~nm}\left(\varepsilon=13,395 \mathrm{M}^{-1} \cdot \mathrm{cm}^{-1}\right), 491 \mathrm{~nm}(\varepsilon=$ $\left.14514 \mathrm{M}^{-1} . \mathrm{cm}^{-1}\right), 416 \mathrm{~nm}\left(\varepsilon=14514 \mathrm{M}^{-1} . \mathrm{cm}^{-1}\right), 321 \mathrm{~nm}\left(\varepsilon=6777 \mathrm{M}^{-1} \cdot \mathrm{cm}^{-1}\right), 302 \mathrm{~nm}\left(\varepsilon=5440 \mathrm{M}^{-}\right.$ $\left.{ }^{1} . \mathrm{cm}^{-1}\right)$, and $267 \mathrm{~nm}\left(\varepsilon=7077 \mathrm{M}^{-1} \cdot \mathrm{cm}^{-1}\right)$. Figure 10 shows natural transition orbitals (NTOs) occupied and unoccupied in the electronic transitions between the ground state (SO) and six low-lying singlet excited states (Sn) of D026 dye (D1).

The data obtained in Fig. 10 of the computed natural transition orbitals (NTOs) indicate that these electronic transitions can be assigned as $\pi-\pi^{\star}$ transitions.

The Hirshfeld population analysis is used to calculate percent contributions of molecular fragments to occupied and unoccupied natural transition orbitals in the electronic transitions between the ground state (S0) and six low-lying singlet excited states (Sn) of D1 obtained at the PCM-B3LYP (Water) /6-311 ++ $\mathrm{G}(\mathrm{d}, \mathrm{p})$ level of approximation and depicted in Table 9.

These data of molecular orbital compositions are essentially based on the percent contributions of urea center, naphthalene right arm (Napth_R), naphthalene left arm (Napth_L), azo-phenyl right arm (Azoph_R) and azo-phenyl left arm (Azoph_L) molecular fragments to the occupied and virtual NTOs.

The first transition $\left(S_{0} \rightarrow S_{1}\right)$, is related to electrons occupied NTO of $p_{z}$ and $p_{x}$ orbitals that mainly localized on 055, 056 and 057 of the sulfonic group (S54-(055, 056 and 057) with contributions of $26 \%, 30 \%$ and $32 \%$, respectively. From these data it is obvious that $\pi$-bonding interaction exists between the $p_{z}$ orbitals of these atoms. The unoccupied NTO is composed of $p_{z}$ orbitals mainly localized on C13, $\mathrm{O} 25$ and N26 of the active group in right naphthalene group with contributions of $\sim 10 \%, 9.5 \%$ and $17 \%$, respectively. From these data it is obvious that $\pi^{\star}$-antibonding interaction exists between the $p_{z}$ orbitals of these atoms. It is clear from data in Table 9 , electron density $\pi \diamond \pi^{\star}$ transition from left arm to right arm by around $17 \%$ of electron localized over the entire molecule.

The second transition $\left(S_{0} \rightarrow S_{2}\right)$, is related to electrons occupied NTO of $p_{z}, p_{x}$ and $p_{y}$ orbitals mainly localized on 022,023 and 024 of the sulphonic group (S21-(022, 023 and 024) with contributions of 
$31 \%, 25 \%$ and $33 \%$, respectively as a result of $\pi$-bonding interaction exists between the $p$ sub-orbitals of these atoms. The non-occupied NTO are composed of $p_{z}$ orbitals that mainly localized on $\mathrm{C13}, 025$ and $\mathrm{N} 26$ of the active group in right naphthalene group as $S_{0} \rightarrow S_{1} . A \pi^{\star}$-antibonding interaction exists between the $p_{z}$ orbitals of these atoms is mainly related electron density $\pi \diamond \pi^{*}$ transition from left arm to right arm by around $20 \%$ of electron localized over the entire molecule.

For the third transition $\left(\mathrm{S}_{0} \rightarrow \mathrm{S}_{3}\right)$, the occupied NTO the $\pi$-bonding interaction is concentrated between the $p_{z}$ orbitals of urea center and left naphthalene arm with 22 and $41 \%$, respectively. The un-occupied NTO is composed of $\mathrm{p}_{\mathrm{z}}$ orbitals that mainly localized on the right naphthalene group and azo-phenyl with contributions of $\sim 30 \%$ and $23 \%$, respectively. $A \pi^{\star}$-antibonding transition may be assigned as $\pi \diamond \pi^{\star}$.interaction exists between the $p_{z}$ orbitals of these atoms.

The fourth transition $\left(\mathrm{S}_{0} \rightarrow \mathrm{S}_{1}\right)$, as a result of electrons occupied NTO is mainly localized on right arm group (C7-H39) with contributions of naphthalene group 47\% and azo-phenyl $50 \%$. The $\pi$-bonding interaction is due to $\pi \diamond \pi^{*}$ transition and exists between the $p_{z}$ orbitals of these range atoms. The unoccupied NTO is found to be mainly localized right naphthalene group with contributions of $\sim 94 \%$. It is mainly occurred due to $\pi^{\star}$-antibonding interaction exists between the $p_{z}$ orbitals of these atoms.

The fifth transition $\left(\mathrm{S}_{0} \rightarrow \mathrm{S}_{5}\right.$ ), as a result of electrons occupied NTO is mainly localized on left arm of naphthalene and azo-phenyl with contributions of $\sim 56 \%$ and $41 \%$, respectively and attributed to $\pi^{-}$ bonding interaction exists between the p sub-orbitals of these atoms. The non-occupied NTO is composed of $p_{z}$ orbitals and mainly localized on right naphthalene group with contribution $\sim 90 \%$. $A \pi^{\star}-$ antibonding transition may be assigned as $\pi \diamond \pi^{*}$ interaction exists between the $p_{z}$ orbitals of these atoms.

For the 6th transition $\left(S_{0} \rightarrow S_{6}\right)$, is essentially related to the occupied NTO $\pi$-bonding electron interactions exist between the $p_{z}$ orbitals of urea center and left naphthalene arm with 47 and $31 \%$. Consequently, the non-occupied NTO is composed of $p_{z}$ orbitals mainly localized left naphthalene group and azo-phenyl left part with contributions of $\sim 45 \%$ and $31 \%$, respectively; resulting in $\pi^{*}$-antibonding interaction leading to $\pi \diamond \pi^{\star}$ transition exists between the $p_{z}$ orbitals of these atoms.

These detailed discussions are confirmed by Fig. 10; which illustrate Natural transition orbitals (NTOs) occupied and unoccupied due to transitions between the ground state (S0) and six low-lying singlet excited states (Sn) of D026 dye (D1) obtained at the PCM-B3LYP (Water) /6-311 ++ G(d,p) level of approximation.. This details discussion clearly shows a $\pi$-bonding interaction among the specific groups of atoms as mentioned above. The NTOs data clearly discussed $\pi$-antibonding interactions among all these contributing species. The nature of vertical electronic transitions in the studied compound (D1) is analyzed via determining the topology of the molecular orbitals involved in these transitions. The NTOs of the first electronic transition ( $\mathrm{SO} \rightarrow \mathrm{S} 1$ ), associated with the ICT band, are given in Fig. 10. It is noticed that both occupied and virtual NTOs demonstrate the typical n-type molecular orbital characteristic. They 
are clearly delocalized over the entire molecule including the two arms. In order to study the extent of charge transfer (CT) or charge redistribution during the excitations, the $\Delta r$ index and variation of dipole moment $\left(\Delta \mu_{C T}\right)$ of excited state with respect to ground state are computed for the studied molecules using Multiwfn code [29]. The obtained data refer to six transitions and calculated parameters are given in Table 10.

The data in Tables 9-11 refer to the variation in the electron density distribution of the occupied NTOs as a symmetry reason to the electron-donating or accepted ability of two arms; which considered as a good evidence of the intramolecular charge transfer nature.

The $\Delta r$ index [52] can be considered as a measure of charge transfer (CT) length. It can be used to discriminate between local $(\Delta \mathbf{r} \leq 1.5 \AA)$ and charge transfer $(\Delta \mathbf{r} \geq 2.0 \AA)$ electronic excitations. According to $\Delta r$ values, it can be seen that the charge transfer character in the six transitions, For $D 1, \Delta r$ has value for $S_{0} \rightarrow S_{1}(7.61 \AA), S_{0} \rightarrow S_{2}(5.36 \AA), S_{0} \rightarrow S_{3}(4.06 \AA), S_{0} \rightarrow S_{4}(3.75 \AA), S_{0} \rightarrow S_{5}(9.22 \AA)$ and $S_{0} \rightarrow S_{6}(4.70$ A) transitions, respectively

\subsection{Correlation between Theoretical and Practical spectral and Electrochemical Oxidation Results of D026:}

The above results show good correlation between both practical and theoretical calculation in the following main points:

- The thermal degradation of the dye at temperature range up to $1000^{\circ} \mathrm{C}$ refer to its very high stability and it required very efficient degradation tools like chemical or electrochemical oxidation to be removed from environment wastewater; which is actual performed in another paper. Most of these thermal fragments are correlated to most of fragment ions appeared in mass spectra of pure powder dye and of GC-mass of dye of electro-oxidation of degradation products.

- The thermal degradation of D026 refer to its high stability of its two symmetrical arms around urea center as correlated to theoretical ESP-mapped surfaces compound (D1) as it decomposed at very high temperature range as a result of charge concentration on some of its essential parts. The dipole moment change upon excitations $\left(\Delta \mu_{\mathrm{CT}}\right)$ is another important factor to assess its $\mathrm{CT}$ behavior.

- The UV-Visible spectrum of D1 is varied; the experimental absorption electronic spectra in water solvent and computed are highly correlated. The calculated absorption maximum wavelengths $\left(\lambda_{\max }\right)$, electronic excitation energies $(\Delta \mathrm{E})$, and oscillator strengths $(f)$ of $\mathrm{D} 1$ in water correlated effectively with the corresponding experimental values. The data obtained of the computed natural transition orbitals (NTOs) indicate that these electronic transitions can be assigned as $\pi-\pi^{\star}$ transitions. These detailed discussions are confirmed; which illustrate Natural transition orbitals (NTOs) occupied and unoccupied due to transitions between the ground state (SO) and six low-lying singlet excited states (Sn) of D026 dye (D1) obtained at the PCM-B3LYP (Water) /6-311 + + G(d,p) level of approximation. 
- The simulated FT-IR spectra at 400 to $4000 \mathrm{~cm}^{-1}$ for D026 in comparison with experimental results refers to the fact that; the dye has two similar arms for the urea derivatives. Each arm is substituted naphthalene and benzene ring linked by diazonium fragment $(=\mathrm{N}-\mathrm{NH}-)$. The $\mathrm{N}-\mathrm{H}$ stretching frequencies of the rings are calculated and found to be in the range $3,473-3,133 \mathrm{~cm}^{-1}$; which is in good agreement with the found values in of 3,200 and $3,500 \mathrm{~cm}^{-1}$ with strong or medium intensities. The inter-molecular hydrogen bonding in D1 is stronger than intra-molecular $\mathrm{H}$-bonding as indicated by difference in calculated and experimental frequencies of the same dye.

\section{Conclusions}

From the obtained data it is concluded that; it is very important to compare between practical thermal and mass results as efficient techniques in studying dye stability, with theoretical results using Gaussian program for structural stability identification of DO26 dye, via careful inspection of various phenomena detected in its two symmetrical arms around urea centre. DFT calculations have been carried out on D026 dye (D1) applying the B3LYP/6-311G method to study the structure characters and vibrational analysis of the tested dye. Highly interesting correlation had been found between experimental and calculated parameters such as bond lengths and vibrational frequencies. Complete assignment of FT-IR spectra vibrational modes of D026 (D1) is successfully performed at wavenumber range 400 to 4000 $\mathrm{cm}^{-1}$. The AIM analyses actually revealed the presence of intra-molecular hydrogen bonding within two arms of the dye molecule. The obtained data successfully characterized them as medium and weak interactions. The effect of hydrogen bonding on structure and vibrational properties of the tested dye had been professionally also discussed. NBO analysis, HOMO-LUMO and MESP plots had been used to explain chemical reactivity of D026 dye (D1) molecule. Various electronic transition parameters have been calculated which actually provide further description and threw more lights on the chemical reactivity and direction of chemical reactions detected in the behavior of D026. From the above calculations and practical work data; the depicted three different tautomeric forms of the D026 (D1) dye are di-keto form $\left(A, C_{13}=O_{25}, C_{46}=O_{58}\right.$ ), keto-enol forms ( $B$ and $C$ ) and di-enol forms ( $D$ and $E$ ) and corresponding four transition states (TS) (F-I) are suggested

The theoretical calculation help effectively to clarifying the thermal fragments correlation to most of fragment ions appeared in mass spectra of pure powder dye and of GC-mass of dye of electro-oxidation degradation products.

\section{Declarations}

Acknowledgement: Authors acknowledge the support of this research by instruments, chemicals and measurements, and programs of Theoretical Calculations given by the Chemistry, Mathematic Departments at Cairo University, and Egyptian Ministry of Health:

\section{Funding: N/A}


Conflict of Interest: The authors declare that they have no conflicts of interest.

Availability of data and material: It is available in transparent forms.

Code Availability: The Gaussian 09W software package has been used for NBO calculations using NBO 3.1 program implemented in the same program. The Gauss View version 5.0.9 [8] involving Chemcraft version 1.6 package

\section{Authors Contributions:}

Mohamed A. Zayed: Writing the manuscript and revision of all of its contents.

Mahmoud A. Noamaan: Made all theoretical calculations and share paper writing.

Zahraa A. M. Abo-Ayad: : Made all experimental work and share paper writing.

\section{References}

1. Abrahart EN (1977) Dyes and their intermediates

2. Acscci Y (2013) Decolorization of Direct Orange 26 by heterogeneous Fenton oxidation. Desalin Water Treat 51:7612-7620

3. Tomczak E, Tosik P (2014) Sorption Equilibrium of Azo Dyes Direct Orange 26 and Reactive Blue 81 onto a Cheap Plant Sorbent/Równowaga Sorpcji Barwników Azowych Direct Orange 26 I Reactive Blue 81 Na Tanim Sorbencie Roślinnym. Ecol Chem Eng S 21:435-445

4. Kaushik CP, Tuteja R, Kaushik N, Sharma JK (2009) Minimization of organic chemical load in direct dyes effluent using low cost adsorbents. Chem Eng J 155:234-240

5. Ghoreishi SM, Behpour M, Farsani AG (2007) Study of interaction between a cationic surfactant and two anionic azo dyes by ion-selective electrode technique and spectrophotometry. Dye Pigment 74:585-589

6. Ji F, Li C, Zhang J, Deng L (2011) Efficient decolorization of dye pollutants with LiFe (WO4) 2 as a reusable heterogeneous Fenton-like catalyst. Desalination 269:284-290

7. Sert $Y$, Ucun $F(2013)$ Vibrational spectroscopic investigation of $p$-, m-and o-nitrobenzonitrile by using Hartree-Fock and density functional theory. Indian J Phys 87:809-818

8. Sert Y, Ucun F, Böyükata M (2013) Vibrational spectroscopic studies of 3-hydroxyphenylboronic acid: molecular structure. Indian J Phys 87:113-119

9. Jeffrey GA, Saenger W (2012) Hydrogen bonding in biological structures. Springer Science \& Business Media

10. Barder R (1990) Atoms in molecules: a quantum theory

11. Jabłonski M, Palusiak M (2010) Basis set and method dependence in atoms in molecules calculations. J Phys Chem A 114:2240-2244 
12. Jissy AK, Konar S, Datta A (2013) Molecular switching behavior in isosteric DNA base pairs. ChemPhysChem 14:1219-1226

13. Abraham SA, Jose D, Datta A (2012) Do Cation ... $\pi$ Interactions Always Need to be 1:1? ChemPhysChem 13:695-698

14. Munch JW (2000) METHOD 528 DETERMINATION OF PHENOLS IN DRINKING WATER BY SOLID PHASE EXTRACTION AND CAPILLARY COLUMN GAS CHROMATOGRAPHY. MASS Spectrom (GC/MS) EPA Test Methods

15. Munch DJ others (2012) METHOD 525.3 DETERMINATION OF SEMIVOLATILE ORGANIC CHEMICALS IN DRINKING WATER BY SOLID PHASE EXTRACTION AND CAPILLARY COLUMN GAS CHROMATOGRAPHY/MASS SPECTROMETRY (GC/MS)

16. Frisch MJ, Trucks GW, Schlegel HB et al (2010) Gaussian 09, Revis. C. 01

17. McLean AD, Chandler GS (1980) Contracted Gaussian basis sets for molecular calculations. I. Second row atoms, $Z=11-18$. J Chem Phys 72:5639-5648

18. Ditchfield R, Hehre WJ, Pople JA (1971) Self-consistent molecular-orbital methods. IX. An extended Gaussian-type basis for molecular-orbital studies of organic molecules. J Chem Phys 54:724-728

19. Becke AD (1988) Density-functional exchange-energy approximation with correct asymptotic behavior. Phys Rev A 38:3098

20. Becke AD (1993) Becke's three parameter hybrid method using the LYP correlation functional. J Chem Phys 98:5648-5652

21. Johnson BG, Frisch MJ (1993) Analytic second derivatives of the gradient-corrected density functional energy. Effect of quadrature weight derivatives. Chem Phys Lett 216:133-140

22. Lee C, Yang W, Parr RG (1988) Development of the Colle-Salvetti correlation-energy formula into a functional of the electron density. Phys Rev vol B 37:785-789

23. Ulic SE, Vedova CO, Della, Hermann A et al (2008) Preparation and Properties of Trifluorothioacetic Acid-S-(trifluoromethyl) ester, CF 3C (0) SCF 3. J Phys Chem A 112:6211-6216

24. Reed AE, Weinhold F (1983) Natural bond orbital analysis of near-Hartree-Fock water dimer. J Chem Phys 78:4066-4073

25. Xu X, Truhlar DG (2011) Accuracy of effective core potentials and basis sets for density functional calculations, including relativistic effects, as illustrated by calculations on arsenic compounds. $J$ Chem Theory Comput 7:2766-2779

26. Khan SA, Rizwan K, Shahid S et al (2020) Synthesis, DFT, computational exploration of chemical reactivity, molecular docking studies of novel formazan metal complexes and their biological applications. Appl Organomet Chem 34:e5444

27. Dennington R, Keith T, Millam J (2009) GaussView, version 5. Semichem Inc Shawnee Mission KS 28. Andrienko GA (2018) Chemcraf program, https://www.chemcraftprog.com

29. Lu T, Chen F (2012) Multiwfn: a multifunctional wavefunction analyzer. J Comput Chem 33:580-592 
30. Runge E, Gross EKU (1984) Density-functional theory for time-dependent systems. Phys Rev Lett 52:997-1000

31. Miertuš S, Scrocco E, Tomasi J (1981) Electrostatic interaction of a solute with a continuum. A direct utilizaion of $A B$ initio molecular potentials for the prevision of solvent effects. Chem Phys 55:117129

32. Miertus S, Tomasi J (1982) Approximate evaluations of the electrostatic free energy and internal energy changes in solution processes. Chem Phys 65:239-245

33. Martin RL (2003) Natural transition orbitals. J Chem Phys 118:4775-4777

34. Guido CA, Cortona P, Mennucci B, Adamo C (2013) On the metric of charge transfer molecular excitations: a simple chemical descriptor. J Chem Theory Comput 9:3118-3126

35. Humphrey W, Dalke A, Schulten K (1996) VMD: visual molecular dynamics. J Mol Graph 14:33-38

36. Teixeira F, Cordeiro MNDS (2018) Improving vibrational mode interpretation using bayesian regression. J Chem Theory Comput 15:456-470

37. Teixeira $F$ (2019) Tools for performing vibrational analysis on molecular systems. Version 122

38. Jamróz MH (2013) Vibrational Energy Distribution Analysis (VEDA): Scopes and limitations. Spectrochim Acta Part A Mol Biomol Spectrosc 114:220-230.

https://doi.org/https://doi.org/10.1016/j.saa.2013.05.096

39. Raghu S, Lee CW, Chellammal S et al (2009) Evaluation of electrochemical oxidation techniques for degradation of dye effluents-A comparative approach. J Hazard Mater 171:748-754

40. Moharreri L, Otadi M, Amiri R, Yeganeh Majd N (2020) Biotreatment of the Wastewater Containing Insoluble Pigment by Halomonas Strain Gb. Prog Color Color Coatings 13:53-62

41. Yeo L, Harris KDM (1999) Temperature-dependent structural properties of a solid urea inclusion compound containing chiral guest molecules: 2-bromotetradecane/urea. Can J Chem 77:2105-2118

42. Custelcean R (2008) Crystal engineering with urea and thiourea hydrogen-bonding groups. Chem Commun 295-307

43. Koch U, Popelier PLA (1995) Characterization of $\mathrm{CHO}$ hydrogen bonds on the basis of the charge density. J Phys Chem 99:9747-9754

44. Rozas I, Alkorta I, Elguero J (2000) Behavior of ylides containing N, O, and C atoms as hydrogen bond acceptors. J Am Chem Soc 122:11154-11161

45. Rajith L, Jissy AK, Kumar KG, Datta A (2011) Mechanistic study for the facile oxidation of trimethoprim on a manganese porphyrin incorporated glassy carbon electrode. J Phys Chem C 115:21858-21864

46. Jose D, Datta A (2011) Role of multicentered bonding in controlling magnetic interactions in $\mathbf{\$} \pi \mathbf{S}$ stacked bis-dithiazolyl radical. Cryst Growth Des 11:3137-3140

47. Espinosa E, Molins E, Lecomte C (1998) Hydrogen bond strengths revealed by topological analyses of experimentally observed electron densities. Chem Phys Lett 285:170-173

48. Steiner T (2002) The hydrogen bond in the solid state. Angew Chemie Int Ed 41:48-76 
49. Emamian S, Lu T, Kruse H, Emamian H (2019) Exploring Nature and Predicting Strength of Hydrogen Bonds: A Correlation Analysis Between Atoms-in-Molecules Descriptors, Binding Energies, and Energy Components of Symmetry-Adapted Perturbation Theory. J Comput Chem 40:2868-2881

50. Alecu IM, Zheng J, Zhao Y, Truhlar DG (2010) Computational thermochemistry: scale factor databases and scale factors for vibrational frequencies obtained from electronic model chemistries. J Chem Theory Comput 6:2872-2887

51. Silverstein RM, Bassler GC (1962) Spectrometric identification of organic compounds. J Chem Educ 39:546

52. Badawi HM (2007) Vibrational spectra and analysis of acetohydrazide $\mathrm{CH} 3-\mathrm{CO}-\mathrm{NH}-\mathrm{NH} 2$. Spectrochim Acta Part A Mol Biomol Spectrosc 67:592-597

53. Pearson RG (1986) Absolute electronegativity and hardness correlated with molecular orbital theory. Proc Natl Acad Sci 83:8440-8441

54. Chandra AK, Uchimara T (2001) NLO and NBO analysis of Sarcosine-maleic acid by using HF and B3LYP calculations. J Phys Chem A 105:3578-3582

55. Liu S-B (2009) Conceptual density functional theory and some recent developments. Acta PhysicoChimica Sin 25:590-600

56. Geerlings P, De Proft F, Langenaeker W (2003) Conceptual density functional theory. Chem Rev 103:1793-1874

57. Chattaraj PK, Roy DR (2007) Update 1 of: electrophilicity index. Chem Rev 107:PR46-PR74

58. Chattaraj PK, Giri S (2007) Stability, reactivity, and aromaticity of compounds of a multivalent superatom. J Phys Chem A 111:11116-11121

59. Yang W, Mortier WJ (1986) The use of global and local molecular parameters for the analysis of the gas-phase basicity of amines. J Am Chem Soc 108:5708-5711

60. Parr RG, Yang W (1984) Density functional approach to the frontier-electron theory of chemical reactivity. J Am Chem Soc 106:4049-4050

61. Parr RG, Pearson RG (1983) Absolute hardness: companion parameter to absolute electronegativity. J Am Chem Soc 105:7512-7516

62. Contreras RR, Fuentealba P, Galvan M, Perez P (1999) A direct evaluation of regional Fukui functions in molecules. Chem Phys Lett 304:405-413

63. Parthasarathi R, Padmanabhan J, Elango M et al (2004) Intermolecular reactivity through the generalized philicity concept. Chem Phys Lett 394:225-230

64. Morell C, Grand A, Toro-Labbe A (2005) New dual descriptor for chemical reactivity. J Phys Chem A 109:205-212

65. Naray-Szabo G, Ferenczy GG (1995) Molecular electrostatics. Chem Rev 95:829-847

66. Luque FJ, Lopez JM, Orozco M (2000) Perspective on "Electrostatic interactions of a solute with a continuum. A direct utilization of ab initio molecular potentials for the prevision of solvent effects". Theor Chem Acc 103:343-345 
67. Murray JS, Politzer P (2011) The electrostatic potential: an overview. Wiley Interdiscip Rev Comput Mol Sci 1:153-163

68. Zhang Y, Shan ZOMZCDG (2019) Antibacterial wastewater flocculant and its preparation method and application in printing and dyeing wastewater treatment. South China Agric Univ Peop Rep China

\section{Tables}

Table 1. The selected bond length $\left(A^{\circ}\right)$, bond angles and dihedral angles, (degree) of D026 dye (D1) at B3lyp/6-311++G(d,p) level of theory. 


\begin{tabular}{|c|c|c|c|c|c|}
\hline Coordinate & Value & Coordinate & Value & Coordinate & Value \\
\hline $\mathrm{R}(\mathrm{C} 1,02)$ & 1.223 & $A(N 3, C 7, C 8)$ & 117.64 & $\mathrm{D}(02, \mathrm{C} 1, \mathrm{~N} 4, \mathrm{C} 40)$ & 5.74 \\
\hline $\mathrm{R}(\mathrm{C} 1, \mathrm{~N} 3)$ & 1.393 & $\mathrm{~A}(\mathrm{~N} 3, \mathrm{C} 7, \mathrm{C16})$ & 122.81 & $\mathrm{D}(\mathrm{N} 3, \mathrm{C} 1, \mathrm{~N} 4, \mathrm{C} 40)$ & -175.86 \\
\hline $\mathrm{R}(\mathrm{C} 1, \mathrm{~N} 4)$ & 1.377 & $\mathrm{~A}(\mathrm{C} 8, \mathrm{C} 7, \mathrm{C} 16)$ & 119.44 & $D(C 1, N 3, C 7, C 8)$ & -151.94 \\
\hline $\mathrm{R}(\mathrm{N} 3, \mathrm{H} 6)$ & 1.010 & $\mathrm{~A}(\mathrm{C} 7, \mathrm{C} 8, \mathrm{C} 9)$ & 121.67 & $\mathrm{D}(\mathrm{C} 1, \mathrm{~N} 3, \mathrm{C} 7, \mathrm{C} 16)$ & 31.98 \\
\hline $\mathrm{R}(\mathrm{N} 3, \mathrm{C7})$ & 1.411 & $A(C 12, C 11, S 21)$ & 121.12 & $\mathrm{D}(\mathrm{C} 1, \mathrm{~N} 4, \mathrm{C} 40, \mathrm{C} 41)$ & -174.24 \\
\hline $\mathrm{R}(\mathrm{N} 4, \mathrm{H} 5)$ & 1.010 & $\mathrm{~A}(\mathrm{C} 11, \mathrm{C} 12, \mathrm{C} 13)$ & 120.19 & $\mathrm{D}(\mathrm{C} 1, \mathrm{~N} 4, \mathrm{C} 40, \mathrm{C} 49)$ & 6.93 \\
\hline $\mathrm{R}(\mathrm{N} 4, \mathrm{C} 40)$ & 1.411 & $A(C 11, C 12, N 26)$ & 116.82 & $\mathrm{D}(\mathrm{N} 3, \mathrm{C} 7, \mathrm{C} 8, \mathrm{C} 9)$ & -175.75 \\
\hline $\mathrm{R}(\mathrm{C} 11, \mathrm{C} 12)$ & 1.454 & $A(C 13, C 12, N 26)$ & 122.99 & $\mathrm{D}(\mathrm{C} 8, \mathrm{C} 9, \mathrm{C} 10, \mathrm{C} 11)$ & -179.19 \\
\hline $\mathrm{R}(\mathrm{C} 11, \mathrm{~S} 21)$ & 1.851 & $A(C 12, C 13, C 14)$ & 117.12 & $\mathrm{D}(\mathrm{C} 8, \mathrm{C} 9, \mathrm{C} 14, \mathrm{C} 13)$ & -179.99 \\
\hline $\mathrm{R}(\mathrm{C} 12, \mathrm{C} 13)$ & 1.475 & $A(C 12, C 13,025)$ & 121.45 & $\mathrm{D}(\mathrm{C} 9, \mathrm{C} 10, \mathrm{C} 11, \mathrm{~S} 21)$ & 178.10 \\
\hline $\mathrm{R}(\mathrm{C} 12, \mathrm{~N} 26)$ & 1.321 & $\mathrm{~A}(\mathrm{~N} 26, \mathrm{~N} 27, \mathrm{C} 28)$ & 119.70 & $\mathrm{D}(\mathrm{C} 11, \mathrm{C} 12, \mathrm{C} 13,025)$ & 179.93 \\
\hline $\mathrm{R}(\mathrm{C} 13,025)$ & 1.252 & $A(N 26, N 27, H 39)$ & 117.77 & $\mathrm{D}(\mathrm{N} 26, \mathrm{C} 12, \mathrm{C} 13, \mathrm{C} 14)$ & -179.42 \\
\hline $\mathrm{R}(\mathrm{N} 26, \mathrm{~N} 27)$ & 1.303 & $\mathrm{~A}(\mathrm{C} 28, \mathrm{~N} 27, \mathrm{H} 39)$ & 122.53 & $\mathrm{D}(\mathrm{N} 26, \mathrm{C} 12, \mathrm{C} 13, \mathrm{O} 25)$ & 0.15 \\
\hline R(N27,C28) & 1.401 & $\mathrm{~A}(\mathrm{~N} 27, \mathrm{C} 28, \mathrm{C} 29)$ & 121.09 & $\mathrm{D}(\mathrm{C} 11, \mathrm{C} 12, \mathrm{~N} 26, \mathrm{~N} 27)$ & 179.90 \\
\hline $\mathrm{R}(\mathrm{N} 27, \mathrm{H} 39)$ & 1.030 & $\mathrm{~A}(\mathrm{~N} 4, \mathrm{C} 40, \mathrm{C} 41)$ & 117.23 & $\mathrm{D}(\mathrm{C} 13, \mathrm{C} 12, \mathrm{~N} 26, \mathrm{~N} 27)$ & -0.32 \\
\hline $\mathrm{R}(\mathrm{C} 44, \mathrm{C} 45)$ & 1.455 & $\mathrm{~A}(\mathrm{~N} 4, \mathrm{C} 40, \mathrm{C} 49)$ & 123.01 & $\mathrm{D}(\mathrm{C} 12, \mathrm{~N} 26, \mathrm{~N} 27, \mathrm{C} 28)$ & 179.75 \\
\hline R(C44,S54) & 1.850 & $A(C 41, C 40, C 49)$ & 119.75 & $\mathrm{D}(\mathrm{C} 12, \mathrm{~N} 26, \mathrm{~N} 27, \mathrm{H} 39)$ & -0.15 \\
\hline $\mathrm{R}(\mathrm{C} 45, \mathrm{C} 46)$ & 1.476 & $\mathrm{~A}(\mathrm{C} 45, \mathrm{C} 44, \mathrm{~S} 54)$ & 120.81 & $\mathrm{D}(\mathrm{N} 26, \mathrm{~N} 27, \mathrm{C} 28, \mathrm{C} 29)$ & -0.30 \\
\hline $\mathrm{R}(\mathrm{C} 45, \mathrm{~N} 59)$ & 1.319 & $\mathrm{~A}(\mathrm{C} 44, \mathrm{C} 45, \mathrm{C} 46)$ & 120.12 & $\mathrm{D}(\mathrm{N} 26, \mathrm{~N} 27, \mathrm{C} 28, \mathrm{C} 33)$ & 179.76 \\
\hline $\mathrm{R}(\mathrm{C} 46,058)$ & 1.253 & $\mathrm{~A}(\mathrm{C} 44, \mathrm{C} 45, \mathrm{~N} 59)$ & 116.82 & $\mathrm{D}(\mathrm{N} 4, \mathrm{C} 40, \mathrm{C} 41, \mathrm{C} 42)$ & -178.74 \\
\hline$R(N 59, N 60)$ & 1.306 & $A(C 46, C 45, N 59)$ & 123.06 & $\mathrm{D}(\mathrm{C} 40, \mathrm{C} 41, \mathrm{C} 42, \mathrm{C} 43)$ & 179.90 \\
\hline R(N60,C61) & 1.400 & $A(C 45, C 46, C 47)$ & 117.16 & $\mathrm{D}(\mathrm{C} 40, \mathrm{C} 41, \mathrm{C} 42, \mathrm{C} 47)$ & -0.06 \\
\hline $\mathrm{R}(\mathrm{N} 60, \mathrm{H} 72)$ & 1.030 & $A(C 45, C 46,058)$ & 121.27 & $\mathrm{D}(\mathrm{C} 41, \mathrm{C} 42, \mathrm{C} 47, \mathrm{C} 46)$ & -179.92 \\
\hline $\mathrm{A}(\mathrm{O} 2, \mathrm{C} 1, \mathrm{~N} 3)$ & 119.22 & $\mathrm{~A}(\mathrm{C} 47, \mathrm{C} 46,058)$ & 121.58 & $\mathrm{D}(\mathrm{N} 59, \mathrm{C} 45, \mathrm{C} 46,058)$ & -0.28 \\
\hline $\mathrm{A}(\mathrm{O} 2, \mathrm{C} 1, \mathrm{~N} 4)$ & 124.90 & A(N59,N60,C61) & 119.48 & $\mathrm{D}(\mathrm{C} 44, \mathrm{C} 45, \mathrm{~N} 59, \mathrm{~N} 60)$ & 179.90 \\
\hline $\mathrm{A}(\mathrm{N} 3, \mathrm{C} 1, \mathrm{~N} 4)$ & 115.86 & $A(N 59, N 60, H 72)$ & 117.72 & $\mathrm{D}(\mathrm{C} 45, \mathrm{~N} 59, \mathrm{~N} 60, \mathrm{C} 61)$ & -179.67 \\
\hline $\mathrm{A}(\mathrm{C} 1, \mathrm{~N} 3, \mathrm{H} 6)$ & 110.27 & $\mathrm{~A}(\mathrm{C} 61, \mathrm{~N} 60, \mathrm{H} 72)$ & 122.80 & $\mathrm{D}(\mathrm{C} 45, \mathrm{~N} 59, \mathrm{~N} 60, \mathrm{H} 72)$ & 0.06 \\
\hline$A(C 1, N 3, C 7)$ & 133.77 & $\mathrm{~A}(\mathrm{~N} 60, \mathrm{C} 61, \mathrm{C} 62)$ & 121.01 & $\mathrm{D}(\mathrm{N} 59, \mathrm{~N} 60, \mathrm{C} 61, \mathrm{C} 62)$ & 0.18 \\
\hline
\end{tabular}




\begin{tabular}{|llllll|}
$\mathrm{A}(\mathrm{H} 6, \mathrm{~N} 3, \mathrm{C} 7)$ & 115.93 & $\mathrm{D}(\mathrm{O} 2, \mathrm{C} 1, \mathrm{~N} 3, \mathrm{H} 6)$ & 11.81 & $\mathrm{D}(\mathrm{N} 60, \mathrm{C} 61, \mathrm{C} 62, \mathrm{C} 63)$ & 179.97 \\
$\mathrm{~A}(\mathrm{C} 1, \mathrm{~N} 4, \mathrm{H} 5)$ & 116.56 & $\mathrm{D}(\mathrm{O} 2, \mathrm{C} 1, \mathrm{~N} 3, \mathrm{C} 7)$ & -170.64 & $\mathrm{D}(\mathrm{C} 41, \mathrm{C} 42, \mathrm{C} 47, \mathrm{C} 48)$ & 0.00 \\
$\mathrm{~A}(\mathrm{C} 1, \mathrm{~N} 4, \mathrm{C} 40)$ & 128.15 & $\mathrm{D}(\mathrm{N} 4, \mathrm{C} 1, \mathrm{~N} 3, \mathrm{H} 6)$ & -166.69 & $\mathrm{D}(\mathrm{C} 44, \mathrm{C} 45, \mathrm{C} 46, \mathrm{O} 58)$ & 179.89 \\
$\mathrm{~A}(\mathrm{H} 5, \mathrm{~N} 4, \mathrm{C} 40)$ & 115.18 & $\mathrm{D}(\mathrm{N} 4, \mathrm{C} 1, \mathrm{~N} 3, \mathrm{C} 7)$ & 10.86 & $\mathrm{D}(\mathrm{N} 59, \mathrm{C} 45, \mathrm{C} 46, \mathrm{C} 47)$ & 179.67 \\
\hline
\end{tabular}

Values are mean $\pm S D$ triplicate assays.

Table 2. The selected geometrical parameters (a.u), bond length $(\AA)$ and binding energy, $(\mathrm{kcal} / \mathrm{mol})$ of D1 at B3lyp/6-311++G(d,p) level of theory.

\begin{tabular}{|c|c|c|c|c|c|c|}
\hline & $\begin{array}{l}\text { N27H39... } \\
025\end{array}$ & $\begin{array}{l}\mathrm{N} 60 \mathrm{H} 72 \ldots \\
058\end{array}$ & $\begin{array}{l}\mathrm{C} 102 \ldots \\
\mathrm{H} 50 \mathrm{C} 49\end{array}$ & $\begin{array}{l}\text { S21023... } \\
\text { H20C10 }\end{array}$ & $\begin{array}{l}\text { S54056... } \\
\text { H53C43 }\end{array}$ & $\begin{array}{l}\text { N4H5... } \\
\text { H17C16 }\end{array}$ \\
\hline HB length $(\AA)$ & 1.764 & 1.766 & 2.211 & 2.334 & 2.345 & 2.135 \\
\hline Density of all electrons & 0.0427 & 0.0428 & 0.0180 & 0.0156 & 0.0159 & 0.0125 \\
\hline $\begin{array}{l}\text { Lagrangian kinetic energy } \\
G(r)\end{array}$ & 0.0379 & 0.0380 & 0.0144 & 0.0133 & 0.0134 & 0.0097 \\
\hline $\begin{array}{l}\text { Hamiltonian kinetic } \\
\text { energy } K(r)\end{array}$ & 0.0015 & 0.0015 & -0.0023 & -0.0020 & -0.0020 & -0.0021 \\
\hline $\begin{array}{l}\text { Potential energy density } \\
V(r)\end{array}$ & -0.0394 & -0.0395 & -0.0121 & -0.0112 & -0.0114 & -0.0076 \\
\hline Energy density $\mathrm{E}(\mathrm{r})$ or $\mathrm{H}(\mathrm{r})$ & -0.0015 & -0.0015 & 0.0023 & 0.0020 & 0.0020 & 0.0021 \\
\hline $\begin{array}{l}\text { Laplacian of electron } \\
\text { density }\end{array}$ & 0.1455 & 0.1458 & 0.0665 & 0.0611 & 0.0618 & 0.0470 \\
\hline $\begin{array}{l}\text { Binding energy of HB } \\
(B E=0.5 \mathrm{~V}(r))[93]\end{array}$ & -12.36 & -12.41 & -3.80 & -3.53 & -3.57 & -2.37 \\
\hline $\begin{array}{l}\text { Binding energy of HB } \\
\text { based on electron density } \\
\text { [95] }\end{array}$ & -8.78 & -8.80 & -3.26 & -2.73 & -2.80 & -2.05 \\
\hline
\end{tabular}

Table 3. Selected vibrational analysis at B3LYP/6-311+G(d,p) level of theory for D1 (corresponding FTIR values are also included) 
$\begin{array}{llll}\text { Freq. } & \text { Sc. } & \text { IR int. FTIR PED \% }{ }^{a} \text { with vibrational assignments } \\ \text { Freq. } & \text { (mode) }\end{array}$

\begin{tabular}{|c|c|c|c|c|}
\hline 3617 & 3473 & 56.5 & & $(-93.2 \%) v(\mathrm{~N} 3 \mathrm{H} 6)+(-6.8 \%) \tau(\mathrm{N} 3 \mathrm{C} 7 \mathrm{C} 16 \mathrm{H} 17)$ \\
\hline 3594 & 3450 & 115.7 & 3466 & $(+100.0 \%) v(\mathbf{N} 4 \mathrm{H} 5)$ \\
\hline 3269 & 3138 & 33.6 & & $(+91.3 \%) v(\mathbf{N} 60 \mathrm{H} 72)+(+8.7 \%) \tau(\mathbf{N} 59 \mathrm{C} 45 \mathrm{C} 46058)$ \\
\hline 3263 & 3133 & 31.3 & & $\begin{array}{l}(+74.1 \%) v(\mathbf{N} 27 \mathbf{H} 39+(+15.8 \%) \tau(\mathbf{H} 39 \mathbf{N} 27 \mathbf{C} 28 \mathbf{C} 33)+(-10.2 \%) y \\
(\mathbf{N} 26 \mathbf{N} 27 \mathbf{C} 28 \mathbf{H} 39)\end{array}$ \\
\hline 3247 & 3117 & 7.8 & 3090 & $(-89.9 \%) v(\mathbf{C} 49 \mathrm{H} 50)+(-10.1 \%) v(\mathbf{C} 48 \mathrm{H} 51)$ \\
\hline 3150 & 3024 & 7.6 & & 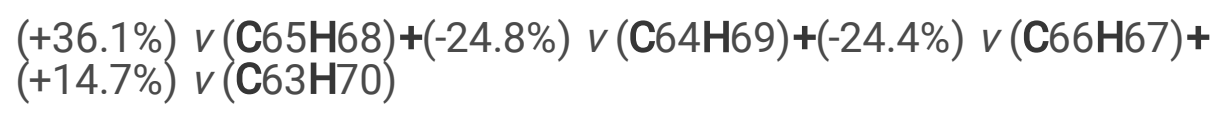 \\
\hline 1742 & 1672 & 668.2 & 1638 & $\begin{array}{l}(+72.3 \%) v(\mathrm{C} 102)+(-10.6 \%) v(\mathrm{C} 1 \mathrm{~N} 4)+(-8.6 \%) \delta(\mathrm{C} 1 \mathrm{~N} 4 \mathrm{H} 5)+ \\
+8.5 \%) \delta(\mathrm{C} 1 \mathrm{~N} 3 \mathrm{H} 6)\end{array}$ \\
\hline 1648 & 1582 & 230.8 & & $(-100.0 \%) v(\mathbf{C} 13025)$ \\
\hline 1640 & 1574 & 83.4 & 1600 & $(-58.3 \%) v(\mathbf{C} 43 \mathbf{C} 44)+(-41.7 \%) v(\mathbf{C} 48 \mathrm{C} 49)$ \\
\hline 1638 & 1573 & 120 & & 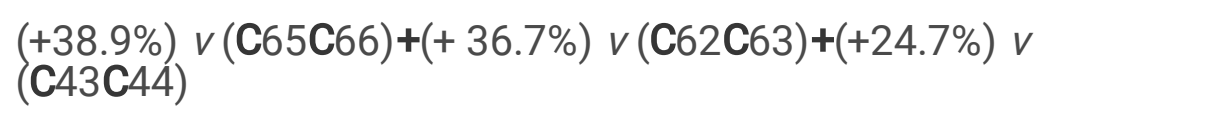 \\
\hline 1637 & 1571 & 239.1 & & $(+64.6 \%) v(\mathbf{C} 10 \mathrm{C} 11)+(+35.4 \%) v(\mathbf{C} 15 \mathrm{C} 16)$ \\
\hline 1624 & 1559 & 34.7 & & $\begin{array}{l}(-27.0 \%) v(\mathbf{C 6 1 C 6 2})+(-26.6 \%) v(\mathbf{C} 10 \mathbf{C 1 1})+(-23.3 \%) v \mathbf{C 6 4 C 6 5 + ( +} \\
22.5 \%) v \text { C63C64 }\end{array}$ \\
\hline 1603 & 1539 & 212 & 1638 & $(-47.2 \%) v(\mathbf{C} 13025)+(-28.6 \%) v(\mathbf{C} 46058)+(-24.2 \%) v(\mathbf{C} 10 \mathbf{C} 11)$ \\
\hline 1597 & 1533 & 300.2 & & $(-66.5 \%) v(\mathbf{C} 46058)+(+34.5 \%) v(\mathbf{C} 13025)$ \\
\hline 1593 & 1529 & 101.3 & 1600 & $(+66.5 \%) v(\mathbf{C} 43 \mathbf{C} 44)+(33.5 \%) v(\mathbf{C} 40 \mathrm{C} 49)$ \\
\hline 1580 & 1516 & 19.9 & & $\begin{array}{l}+34.3 \%) v(\mathbf{C} 7 \mathbf{C} 16)+(+24.3 \%) v(\mathbf{C} 10 \mathbf{C 1 1})+(-23.0 \%) v(\mathbf{C} 14 \mathbf{C} 15)+ \\
+18.3 \%) v(\mathbf{C} 9 \mathbf{C} 14)\end{array}$ \\
\hline 1561 & 1499 & 218.9 & 1490 & $(+100 \%) v(\mathbf{C} 12 \mathbf{N} 26)$ \\
\hline 1558 & 1496 & 526.6 & & $\begin{array}{l}(+33.2 \%) v(\mathbf{C} 45 \mathbf{N} 59)+(+22.5 \%) v(\mathbf{C} 12 \mathbf{N} 26)+(-22.5 \%) v \\
(\mathbf{N} 59 \mathbf{N} 60)+(+21.8 \%) \delta \mathbf{N} 59(\mathbf{N} 60 \mathbf{H} 72)\end{array}$ \\
\hline 1525 & 1464 & 41.6 & & 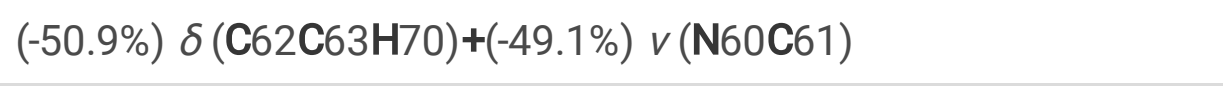 \\
\hline 1441 & 1384 & 129.3 & & $(-38.6 \%) v(\mathbf{C} 45 \mathbf{N} 59)+(+33.0 \%) v(\mathbf{C} 41 \mathbf{C} 42)+(+29.0 \%) v(\mathbf{C} 44 \mathbf{C} 45)$ \\
\hline 1426 & 1369 & 526.1 & 1300 & $(-100 \%) v(\mathbf{C} 45$ N59) \\
\hline 1414 & 1357 & 365 & & $(-100 \%) v(\mathbf{C} 12 \mathbf{N} 26)$ \\
\hline 1380 & 1325 & 61.4 & & $(-100 \%) v(\mathrm{C} 44 \mathrm{C} 45)$ \\
\hline 1316 & 1263 & 56.9 & 1250 & $(+100 \%) v(\mathbf{N} 26 \mathbf{N} 27)$ \\
\hline
\end{tabular}




\begin{tabular}{|c|c|c|c|c|}
\hline 1294 & 1242 & 232.3 & & $(+100.0 \%) v(\mathbf{N} 4 \mathbf{C} 40)$ \\
\hline 1265 & 1214 & 1336.6 & & $(+56.7 \%) v(\mathrm{C} 1 \mathrm{~N} 3)+(-43.3 \%) v(\mathrm{C} 1 \mathrm{~N} 4)$ \\
\hline 1254 & 1203 & 804 & & $(+100.0 \%) v(\mathbf{N} 59 \mathbf{N} 60)$ \\
\hline 1196 & 1148 & 213.6 & \multirow[t]{2}{*}{1150} & $(-100.0 \%) v(\mathbf{S} 54056)$ \\
\hline 1193 & 1145 & 245 & & $(+100.0 \%) v(\mathbf{S} 21023)$ \\
\hline 1187 & 1140 & 80 & & $(+100.0 \%) \delta(\mathrm{C} 65 \mathrm{C} 66 \mathrm{H} 67)$ \\
\hline 1186 & 1138 & 443.2 & 1120 & $(+100.0 \%) v(\mathbf{C} 28 \mathrm{C} 33)$ \\
\hline 1173 & 1126 & 289.4 & \multirow[t]{2}{*}{1110} & $(-53.4 \%) v(\mathbf{S} 21024)+(+64.6 \%) v(\mathbf{S} 21022)$ \\
\hline 1163 & 1117 & 102.3 & & $(+48.3 \%) v(\mathbf{S} 21023)+(-32.1 \%) v(\mathbf{S} 21022)+(-19.6 \%) v(\mathbf{S} 21024)$ \\
\hline 757 & 727 & 59.2 & \multirow[t]{2}{*}{730} & 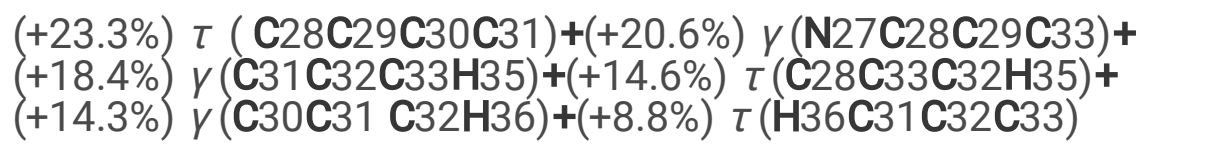 \\
\hline 757 & 727 & 62.2 & & 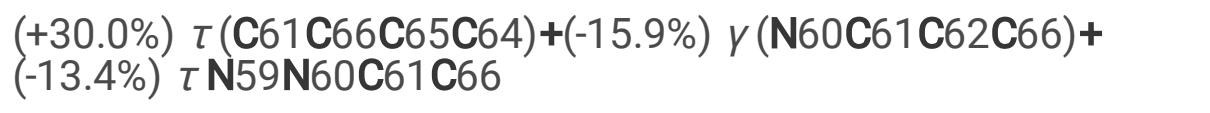 \\
\hline 679 & 652 & 23.6 & \multirow[t]{4}{*}{615} & $(+100.0 \%) \delta(\mathbf{C 7 C 8 C 9 )}$ \\
\hline 648 & 623 & 22 & & $(+100.0 \%) v(\mathbf{C} 29 \mathbf{C} 30)$ \\
\hline 637 & 611 & 57.2 & & $(+100.0 \%) v(\mathbf{C} 44 \mathrm{C} 45)$ \\
\hline 632 & 607 & 82.8 & & $(+100.0 \%) \delta(\mathbf{C} 31$ C32C33) \\
\hline 628 & 603 & 35.5 & \multirow[t]{3}{*}{597} & $(+100.0 \%) \delta($ C31C32C33) \\
\hline 623 & 598 & 21.9 & & $(+100.0 \%) \gamma(\mathbf{N} 3 \mathbf{C} 7 \mathrm{C} 8 \mathrm{C} 16)$ \\
\hline 622 & 597 & 19.2 & & $\left\{\begin{array}{l}+40.2 \%) y(\mathbf{N} 4 \mathrm{C} 40 \mathrm{C} 41 \mathrm{C} 49)+(-29.9 \%) \tau(\mathbf{C} 43 \mathrm{C} 42 \mathrm{C} 47 \mathrm{C} 48)+ \\
(-29.9 \%) y(\mathbf{C} 43 \mathbf{C} 44 \mathbf{C} 45 \mathbf{S} 54)\end{array}\right.$ \\
\hline 592 & 568 & 20.4 & & $(+100.0 \%) v(\mathbf{C 4 6 C 4 7 )}$ \\
\hline 588 & 564 & 69.3 & 560 & $(-64.2 \%) \delta(\mathbf{C} 8 \mathbf{C} 9 \mathbf{C} 14)+(+35.8 \%) \delta(\mathbf{C} 13 \mathbf{C} 14 \mathbf{C} 15)$ \\
\hline 578 & 555 & 79.3 & & $(+100.0 \%) \delta(\mathbf{C} 40 \mathrm{C} 41 \mathrm{C} 42)$ \\
\hline 557 & 535 & 27.2 & & $(+100.0 \%) v(\mathbf{N} 4 \mathbf{C} 40)$ \\
\hline 545 & 523 & 21.8 & 520 & $(-100.0 \%) v(\mathrm{C} 13 \mathrm{C} 14)$ \\
\hline 511 & 490 & 36.6 & & $(-100.0 \%) \delta(\mathbf{C} 45 \mathbf{C} 46 \mathbf{C} 47)$ \\
\hline 508 & 488 & 1.4 & 480 & $(-51.0 \%) \delta(\mathbf{C} 29 \mathbf{C} 28 \mathbf{C} 33)+(-49.0 \%) v(\mathbf{C} 12 \mathbf{C 1 3})$ \\
\hline 477 & 458 & 4 & 450 & $\begin{array}{l}(-41.2 \%) \delta(\mathbf{C} 45 \mathrm{C} 46058)+(-29.9 \%) v(\mathrm{C} 45 \mathrm{C} 46)+(-28.9 \%) \delta \\
(\mathrm{C} 46 \mathrm{C} 45 \text { N59) }\end{array}$ \\
\hline 428 & 411 & 17.2 & 400 & $(+100.0 \%) \delta(\mathbf{C} 13 \mathbf{C} 14 \mathbf{C} 15)$ \\
\hline
\end{tabular}


$425 \quad 408 \quad 11.7$

$(-100.0 \%) \tau($ C43C42C47C48)

$419 \quad 402 \quad 38$

$(+100.0 \%) \delta(\mathbf{C} 13 \mathrm{C} 14 \mathrm{C} 15)$

${ }^{\text {a }} \mathrm{PED}<10 \%$ are not included in assignments.

${ }^{b}$ Symbols: $v=$ Stretching, $\delta=$ Bending, $\tau$ and $\gamma=$ torsional motions, $+=$ out of phase, $-=$ in phase

Expressions represent: (direction of phase, percentage contribution in normal mode\%) vibrational normal mode (Atom composition mode motions)

Table 4. Natural charge of selected atoms of D026 dye1 (D1) at B3lyp/6-311++G(d,p) level of theory. 


\begin{tabular}{|c|c|c|c|c|c|}
\hline Atoms & Charge & Atoms & Charge & Atoms & Charge \\
\hline C1 & 0.817 & 025 & -0.666 & C49 & -0.261 \\
\hline 02 & -0.661 & N26 & -0.153 & H50 & 0.241 \\
\hline N3 & -0.63 & N27 & -0.272 & H51 & 0.223 \\
\hline N4 & -0.623 & $\mathrm{C} 28$ & 0.135 & H52 & 0.202 \\
\hline H5 & 0.403 & C29 & -0.209 & H53 & 0.241 \\
\hline H6 & 0.401 & $\mathrm{C} 30$ & -0.189 & S54 & 2.298 \\
\hline C7 & 0.161 & C31 & -0.234 & 055 & -0.984 \\
\hline C8 & -0.24 & $\mathrm{C} 32$ & -0.204 & 056 & -0.999 \\
\hline C9 & 0.113 & C33 & -0.231 & 057 & -0.985 \\
\hline C10 & -0.262 & H34 & 0.205 & 058 & -0.671 \\
\hline C11 & -0.207 & H35 & 0.195 & N59 & -0.187 \\
\hline C12 & 0.03 & H36 & 0.194 & N60 & -0.282 \\
\hline C13 & 0.484 & H37 & 0.202 & C61 & 0.137 \\
\hline C14 & -0.197 & H38 & 0.267 & C62 & -0.21 \\
\hline C15 & -0.115 & H39 & 0.417 & C63 & -0.189 \\
\hline C16 & -0.287 & $\mathrm{C} 40$ & 0.181 & C64 & -0.238 \\
\hline H17 & 0.213 & C41 & -0.214 & C65 & -0.206 \\
\hline H18 & 0.229 & $\mathrm{C} 42$ & -0.014 & C66 & -0.235 \\
\hline H19 & 0.201 & $\mathrm{C} 43$ & -0.222 & H67 & 0.202 \\
\hline $\mathrm{H} 2 \mathrm{O}$ & 0.24 & C44 & -0.256 & H68 & 0.193 \\
\hline S21 & 2.299 & C45 & 0.16 & H69 & 0.193 \\
\hline 022 & -0.983 & C46 & 0.454 & $\mathrm{H} 70$ & 0.201 \\
\hline 023 & -1.001 & C47 & -0.166 & H71 & 0.268 \\
\hline 024 & -0.981 & C48 & -0.12 & H72 & 0.415 \\
\hline
\end{tabular}

Values are mean $\pm S D$ triplicate assays.

Table 5. Energetic parameters and reactivity indices of synthesized D026 dye1 (D1) at B3lyp/6$311++G(d, p)$ level of theory. 


\begin{tabular}{llllllll} 
Parameters & ET,au & EHOMO,au & ELUMO,au & Eg,eV & l,eV & A,eV & $\mu$, D \\
\hline D1 & -3073.35409 & -0.06336 & 0.02557 & 2.42 & 1.72 & -0.70 & 10.98 \\
\hline Parameters & X,eV & n,eV & S,eV & V,eV & $\omega, \mathrm{eV}$ & $\mathbf{N}, \mathbf{e V}$ & \\
\hline D1 & 0.51 & 1.21 & 0.41 & -0.51 & 0.11 & 2.49 &
\end{tabular}

Values are mean $\pm S D$ triplicate assays.

Table 6. Values of the Fukui functions and Dual descriptor of DO26 dye (D1) at B3lyp/6-311++G(d,p) level of calculation. 


\begin{tabular}{|c|c|c|c|c|c|c|c|}
\hline Atom & $f(-)$ & $f(+)$ & $\Delta f$ & Atom & $f(-)$ & $f(+)$ & $\Delta f$ \\
\hline C1 & 0.000 & 0.007 & 0.007 & $\mathrm{C} 28$ & 0.000 & 0.015 & 0.015 \\
\hline 02 & 0.000 & 0.009 & 0.009 & C29 & 0.000 & 0.034 & 0.034 \\
\hline N3 & 0.000 & 0.009 & 0.009 & C30 & 0.000 & 0.003 & 0.003 \\
\hline N4 & 0.000 & 0.000 & 0.000 & C31 & 0.000 & 0.040 & 0.040 \\
\hline C7 & 0.000 & 0.053 & 0.053 & C32 & 0.000 & 0.007 & 0.007 \\
\hline C8 & 0.000 & 0.004 & 0.004 & C33 & 0.000 & 0.023 & 0.023 \\
\hline C9 & 0.000 & 0.051 & 0.051 & H39 & 0.000 & 0.001 & 0.001 \\
\hline C10 & 0.000 & 0.018 & 0.018 & C40 & 0.000 & 0.008 & 0.007 \\
\hline C11 & 0.000 & 0.037 & 0.037 & C41 & 0.000 & 0.000 & 0.000 \\
\hline C12 & 0.000 & 0.021 & 0.021 & C47 & 0.000 & 0.004 & 0.004 \\
\hline C13 & 0.000 & 0.131 & 0.131 & C48 & 0.000 & 0.003 & 0.003 \\
\hline C14 & 0.000 & 0.036 & 0.036 & 055 & 0.333 & 0.000 & -0.333 \\
\hline C15 & 0.000 & 0.044 & 0.044 & 056 & 0.324 & 0.000 & -0.324 \\
\hline C16 & 0.000 & 0.013 & 0.013 & 057 & 0.334 & 0.000 & -0.334 \\
\hline S21 & 0.000 & 0.000 & 0.000 & 058 & 0.001 & 0.007 & 0.006 \\
\hline 022 & 0.000 & 0.002 & 0.002 & N59 & 0.001 & 0.012 & 0.011 \\
\hline 023 & 0.000 & 0.000 & 0.000 & N60 & 0.000 & 0.005 & 0.005 \\
\hline 024 & 0.000 & 0.002 & 0.002 & C61 & -0.001 & 0.001 & 0.002 \\
\hline 025 & 0.000 & 0.100 & 0.100 & C62 & 0.003 & 0.002 & -0.001 \\
\hline N26 & 0.000 & 0.200 & 0.200 & C63 & -0.001 & 0.000 & 0.001 \\
\hline N27 & 0.000 & 0.075 & 0.075 & & & & \\
\hline
\end{tabular}

Values are mean $\pm S D$ triplicate assays

Table 7. Values of the Condensed local Softnesses (Hartree*e), relative electrophilicity/nucleophilicity (dimensionless) and the Condensed local electrophilicity (ElectroP)/nucleophilicity (NucleoP) index $\left(e^{*} \mathrm{eV}\right)$ of D026 dye (D1) at B3lyp/6-311++G(d,p) level of calculation. 


\begin{tabular}{|c|c|c|c|c|c|c|c|c|}
\hline Atoms & $\mathbf{s}^{-}$ & $s^{+}$ & Atoms & $s^{+} / s^{-}$ & $s^{-} / s^{+}$ & Atoms & ElectroP & NucleoP \\
\hline C1 & -0.076 & -0.027 & C1 & 0.36 & 2.78 & $\mathrm{C} 1$ & 0.000 & -0.094 \\
\hline 02 & -0.144 & -0.075 & 02 & 0.52 & 1.92 & 02 & -0.001 & -0.178 \\
\hline N3 & -0.039 & -0.026 & N3 & 0.67 & 1.49 & N3 & 0.000 & -0.048 \\
\hline N4 & -0.020 & -0.015 & N4 & 0.73 & 1.36 & N4 & 0.000 & -0.024 \\
\hline $\mathrm{C7}$ & -0.125 & -0.032 & $\mathrm{C7}$ & 0.25 & 3.95 & $\mathrm{C7}$ & 0.000 & -0.154 \\
\hline C8 & -0.070 & -0.059 & C8 & 0.84 & 1.19 & C8 & 0.000 & -0.086 \\
\hline C9 & -0.094 & -0.010 & C9 & 0.11 & 9.23 & C9 & 0.000 & -0.117 \\
\hline C10 & -0.087 & -0.114 & C10 & 1.30 & 0.77 & C10 & -0.001 & -0.108 \\
\hline C11 & -0.053 & -0.014 & C11 & 0.27 & 3.73 & C11 & 0.000 & -0.066 \\
\hline C12 & -0.071 & -0.036 & C12 & 0.51 & 1.97 & $\mathrm{C} 12$ & 0.000 & -0.088 \\
\hline C13 & -0.203 & -0.029 & $\mathrm{C} 13$ & 0.14 & 6.94 & $\mathrm{C} 13$ & 0.000 & -0.250 \\
\hline C14 & -0.062 & -0.027 & C14 & 0.43 & 2.34 & C14 & 0.000 & -0.077 \\
\hline C15 & -0.091 & -0.039 & C15 & 0.42 & 2.36 & C15 & 0.000 & -0.113 \\
\hline C16 & -0.076 & -0.052 & C16 & 0.68 & 1.46 & C16 & 0.000 & -0.094 \\
\hline S21 & -0.046 & -0.189 & S21 & 4.08 & 0.25 & S21 & -0.001 & -0.057 \\
\hline 022 & -0.073 & -0.418 & 022 & 5.69 & 0.18 & 022 & -0.003 & -0.091 \\
\hline 023 & -0.099 & -0.337 & 023 & 3.40 & 0.29 & 023 & -0.002 & -0.123 \\
\hline 024 & -0.070 & -0.411 & 024 & 5.84 & 0.17 & 024 & -0.003 & -0.087 \\
\hline 025 & -0.252 & -0.089 & 025 & 0.35 & 2.83 & 025 & -0.001 & -0.311 \\
\hline N26 & -0.294 & -0.002 & N26 & 0.01 & 176.82 & N26 & 0.000 & -0.364 \\
\hline N27 & -0.145 & -0.090 & $\mathrm{~N} 27$ & 0.62 & 1.60 & N27 & -0.001 & -0.179 \\
\hline C28 & -0.021 & 0.000 & $\mathrm{C} 28$ & -0.01 & -101.57 & $\mathrm{C} 28$ & 0.000 & -0.026 \\
\hline C29 & -0.080 & -0.018 & C29 & 0.22 & 4.52 & $\mathrm{C} 29$ & 0.000 & -0.099 \\
\hline C30 & -0.089 & -0.046 & C30 & 0.51 & 1.95 & C30 & 0.000 & -0.110 \\
\hline C31 & -0.173 & -0.103 & C31 & 0.60 & 1.67 & C31 & -0.001 & -0.214 \\
\hline C32 & -0.097 & -0.063 & C32 & 0.65 & 1.55 & C32 & 0.000 & -0.119 \\
\hline C33 & -0.078 & -0.052 & C33 & 0.66 & 1.52 & C33 & 0.000 & -0.097 \\
\hline $\mathrm{C} 40$ & -0.083 & -0.052 & C40 & 0.62 & 1.61 & $\mathrm{C} 40$ & 0.000 & -0.103 \\
\hline
\end{tabular}




\begin{tabular}{lllllllll} 
C41 & -0.040 & -0.074 & C41 & 1.85 & 0.54 & C41 & -0.001 & -0.049 \\
\hline C42 & -0.072 & -0.007 & C42 & 0.10 & 10.25 & C42 & 0.000 & -0.088 \\
\hline C47 & -0.054 & -0.034 & C47 & 0.63 & 1.59 & C47 & 0.000 & -0.067 \\
\hline C48 & -0.089 & -0.074 & C48 & 0.83 & 1.21 & C48 & -0.001 & -0.110 \\
\hline C49 & -0.071 & -0.106 & C49 & 1.50 & 0.67 & C49 & -0.001 & -0.087 \\
\hline S54 & -0.037 & -0.195 & S54 & 5.21 & 0.19 & S54 & -0.001 & -0.046 \\
\hline O55 & -0.062 & -0.442 & O55 & 7.09 & 0.14 & 055 & -0.003 & -0.077 \\
\hline O56 & -0.068 & -0.324 & O56 & 4.75 & 0.21 & 056 & -0.002 & -0.084 \\
\hline O57 & -0.065 & -0.442 & O57 & 6.76 & 0.15 & 057 & -0.003 & -0.081 \\
\hline O58 & -0.218 & -0.138 & 058 & 0.63 & 1.59 & 058 & -0.001 & -0.270 \\
\hline N59 & -0.243 & -0.015 & N59 & 0.06 & 15.82 & N59 & 0.000 & -0.300 \\
\hline N60 & -0.118 & -0.128 & N60 & 1.08 & 0.92 & N60 & -0.001 & -0.146 \\
\hline C61 & -0.019 & -0.006 & C61 & 0.30 & 3.33 & C61 & 0.000 & -0.023 \\
\hline C62 & -0.065 & -0.030 & C62 & 0.46 & 2.20 & C62 & 0.000 & -0.080 \\
\hline C63 & -0.074 & -0.056 & C63 & 0.75 & 1.33 & C63 & 0.000 & -0.092
\end{tabular}

Table 8: Absorption maximum wavelengths $\left(I_{\max }\right)$, electronic excitation energies, and oscillator strengths of D1 in water.

\begin{tabular}{|c|c|c|c|c|c|c|c|}
\hline & $I_{\max }$ & m) & $\varepsilon\left(\mathrm{mol}^{-1} . \mathrm{cm}^{-}\right.$ & $f$ & $\Delta E($ & & Transition \\
\hline & Exp. & TD-DFT & Exp. & & Exp. & $\begin{array}{l}\text { TD- } \\
\text { DFT }\end{array}$ & \\
\hline$S_{0} \rightarrow S_{1}$ & 511 & 475 (HàL(0.5403)) & 13,395 & 1.19 & 2.43 & 2.61 & $\pi \rightarrow \pi^{*}$ \\
\hline$S_{0} \rightarrow S_{2}$ & 491 & 466 (H-1àL(0.584)) & 14,514 & 0.25 & 2.53 & 2.66 & $\pi \rightarrow \pi^{*}$ \\
\hline$S_{0} \rightarrow S_{3}$ & 416 & 412 (H-2àL(0.629)) & 6,777 & 0.44 & 2.98 & 3.00 & $\pi \rightarrow \pi^{*}$ \\
\hline$S_{0} \rightarrow S_{4}$ & 321 & $\begin{array}{l}319(\mathrm{H}- \\
1 \mathrm{àL}+2(0.492))\end{array}$ & 5,440 & 0.21 & 3.86 & 3.88 & $\pi \rightarrow \pi^{*}$ \\
\hline$S_{0} \rightarrow S_{5}$ & 302 & $\begin{array}{l}303 \\
(\mathrm{HàL}+2(0.616))\end{array}$ & 8,313 & 0.03 & 4.11 & 4.1 & $\pi \rightarrow \pi^{*}$ \\
\hline$S_{0} \rightarrow S_{6}$ & 272 & $\begin{array}{l}267(\mathrm{H}- \\
12 a ̀ \mathrm{~L}+1(0.239))\end{array}$ & 7,077 & 0.02 & 4.54 & 4.64 & $\pi \rightarrow \pi^{*}$ \\
\hline
\end{tabular}


Table 9. Percent contributions of molecular fragments to occupied and unoccupied natural transition orbitals in the electronic transitions between the ground state $\left(\mathrm{S}_{0}\right)$ and six low-lying singlet excited states $\left(S_{n}\right)$ of D1 obtained at the PCM-B3LYP (Water) /6-311++G(d,p) level of approximation using Hirshfeld population analysis.

\begin{tabular}{|c|c|c|c|c|c|c|c|c|}
\hline & & $\begin{array}{l}\text { Urea } \\
\text { Center }\end{array}$ & Napth_R & AzoPh_R & Napth_L & AzoPh_L & $\begin{array}{l}\text { Right- } \\
\text { arm }\end{array}$ & $\begin{array}{l}\text { Left- } \\
\text { arm }\end{array}$ \\
\hline \multirow[t]{2}{*}{$\mathrm{S}_{0} \circledast \mathrm{S}_{1}$} & Occ.NTO & 2.61 & 20.08 & 15.06 & 35.24 & 26.63 & 35.15 & 61.87 \\
\hline & Virt.NTO & 3.68 & 29.90 & 21.66 & 25.52 & 18.82 & 51.56 & 44.33 \\
\hline \multirow[t]{2}{*}{$S_{0} \circledast S_{2}$} & Occ.NTO & 0.69 & 35.88 & 22.17 & 24.56 & 16.10 & 58.05 & 40.66 \\
\hline & Virt.NTO & 3.33 & 42.47 & 31.90 & 12.58 & 9.10 & 74.37 & 21.68 \\
\hline \multirow[t]{2}{*}{$S_{0} \circledast S_{3}$} & Occ.NTO & 21.04 & 34.41 & 1.50 & 41.02 & 1.96 & 35.91 & 42.97 \\
\hline & Virt.NTO & 3.69 & 29.82 & 22.12 & 24.88 & 19.04 & 51.95 & 43.92 \\
\hline \multirow[t]{2}{*}{$S_{0} \circledast S_{4}$} & Occ.NTO & 1.22 & 46.73 & 49.27 & 0.89 & 0.56 & 96.00 & 1.44 \\
\hline & Virt.NTO & 3.38 & 93.73 & 0.94 & 1.60 & 0.25 & 94.66 & 1.85 \\
\hline \multirow[t]{2}{*}{$S_{0} \circledast S_{5}$} & Occ.NTO & 2.33 & 1.04 & 0.01 & 55.37 & 41.25 & 1.05 & 96.62 \\
\hline & Virt.NTO & 3.53 & 89.14 & 0.96 & 6.17 & 0.10 & 90.09 & 6.27 \\
\hline \multirow[t]{2}{*}{$\mathrm{S}_{0} \circledast \mathrm{S}_{6}$} & Occ.NTO & 46.25 & 3.61 & 1.34 & 31.65 & 17.14 & 4.95 & 48.79 \\
\hline & Virt.NTO & 5.27 & 12.39 & 7.42 & 44.02 & 30.75 & 19.81 & 74.77 \\
\hline
\end{tabular}

Table 10. Charge transfer (CT) length $(\Delta r)$ and variation in dipole moment $\left(\Delta \mathrm{m}_{\mathrm{CT}}\right)$ indices of the six electronic excitations for the studied D1 obtained at the PCM-B3LYP(Water)/6-311++G(d,p) level of approximation.

\begin{tabular}{lllllll} 
& $\mathrm{S}_{0} \circledast \mathrm{S}_{1}$ & $\mathrm{~S}_{0} \circledast \mathrm{S}_{2}$ & $\mathrm{~S}_{0} \circledast \mathrm{S}_{\mathbf{3}}$ & $\mathrm{S}_{\mathbf{0}} \circledast \mathrm{S}_{\mathbf{4}}$ & $\mathrm{S}_{\mathbf{0}} \circledast \mathrm{S}_{5}$ & $\mathrm{~S}_{0} \circledast \mathrm{S}_{6}$ \\
\hline$\Delta r(\AA)$ & 7.61 & 5.36 & 4.06 & 3.75 & 9.22 & 4.70 \\
\hline$\Delta m_{\mathrm{CT}}$ (a.u.) & 3.34 & 2.12 & 2.94 & 7.10 & 7.10 & 2.17
\end{tabular}

\section{Figures}



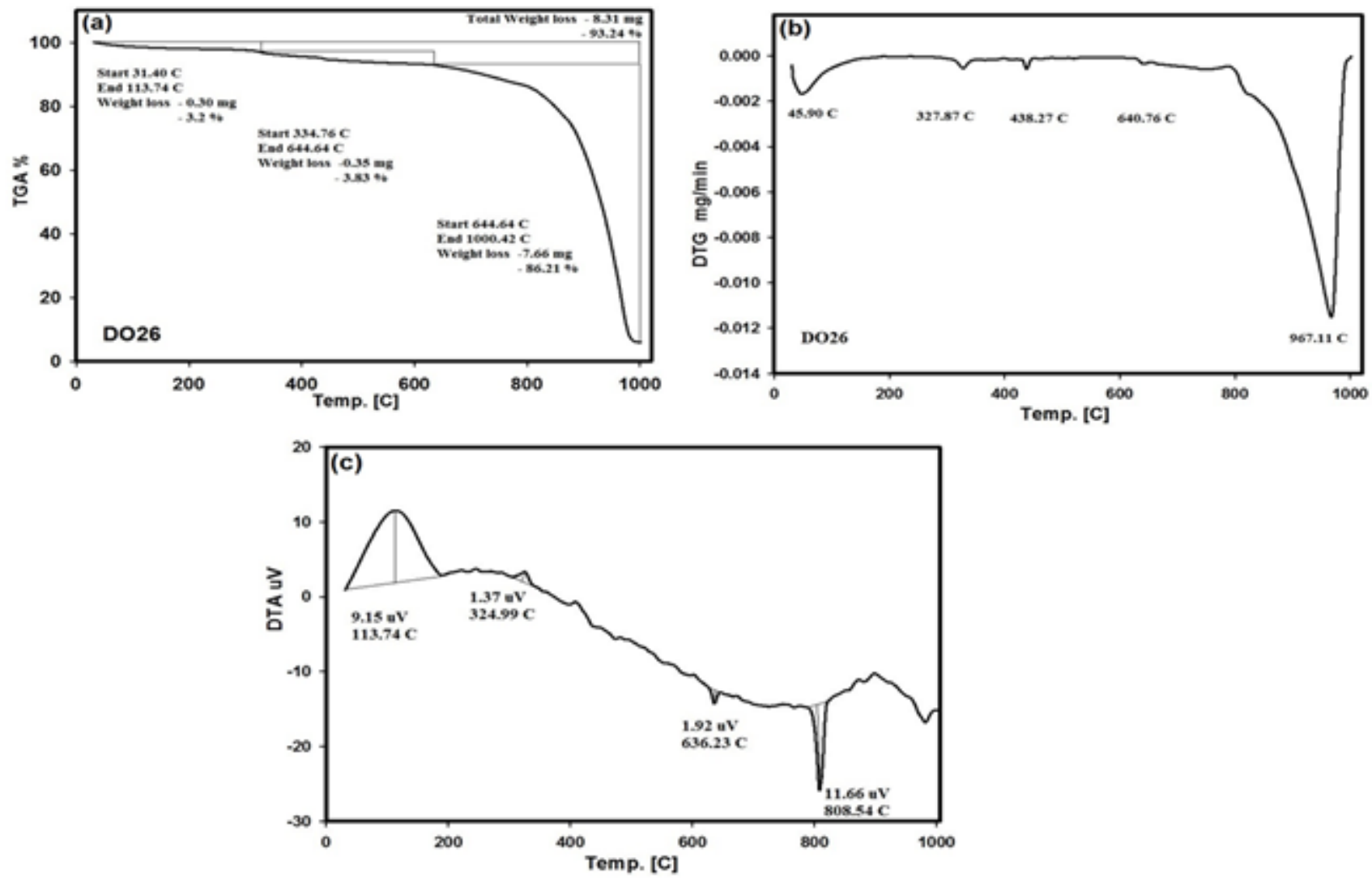

Figure 1

Thermal Analyses of Direct Orange 26 (D026)

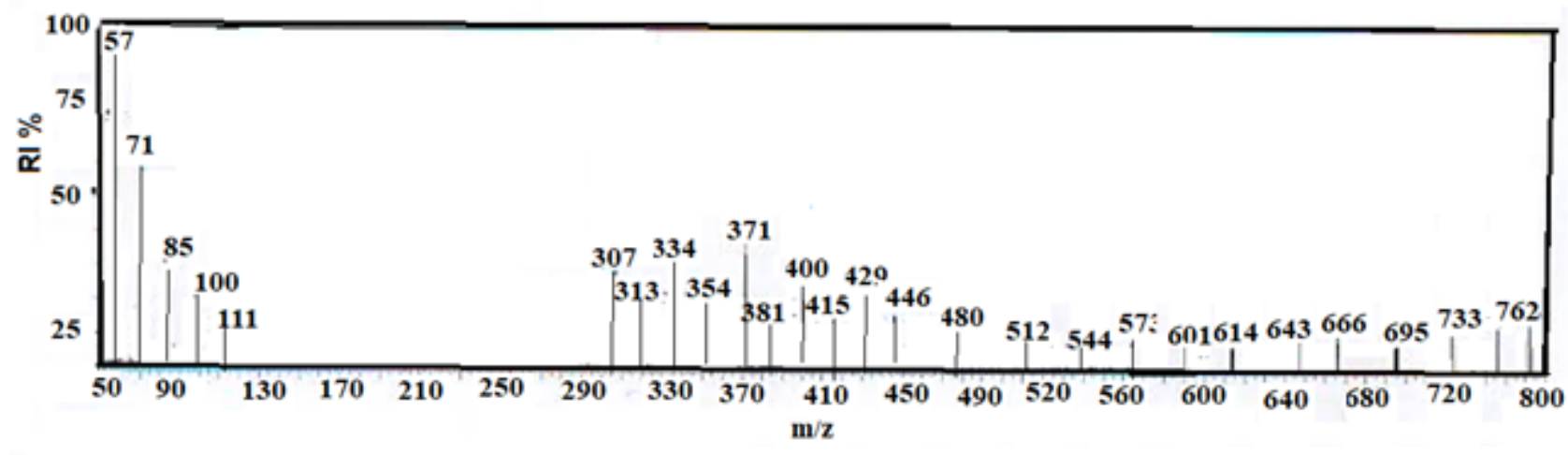

Figure 2

Mass spectra of D026 pure powder. 


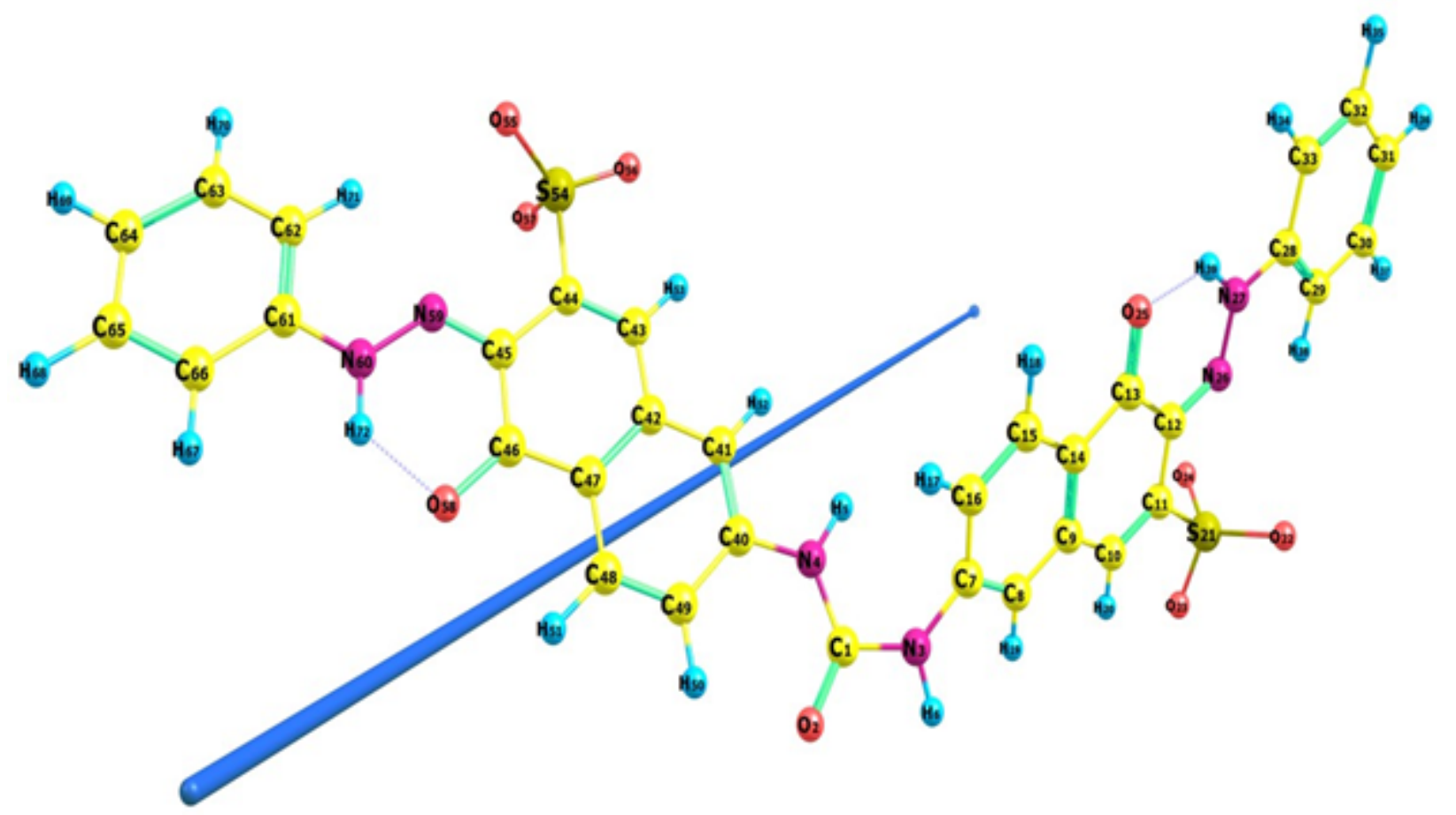

Figure 3

The optimized geometry, numbering system, vector of dipole moment of D0-26 dye (D1) compounds using B3LYP/6-311++G(d,p) level of calculation.

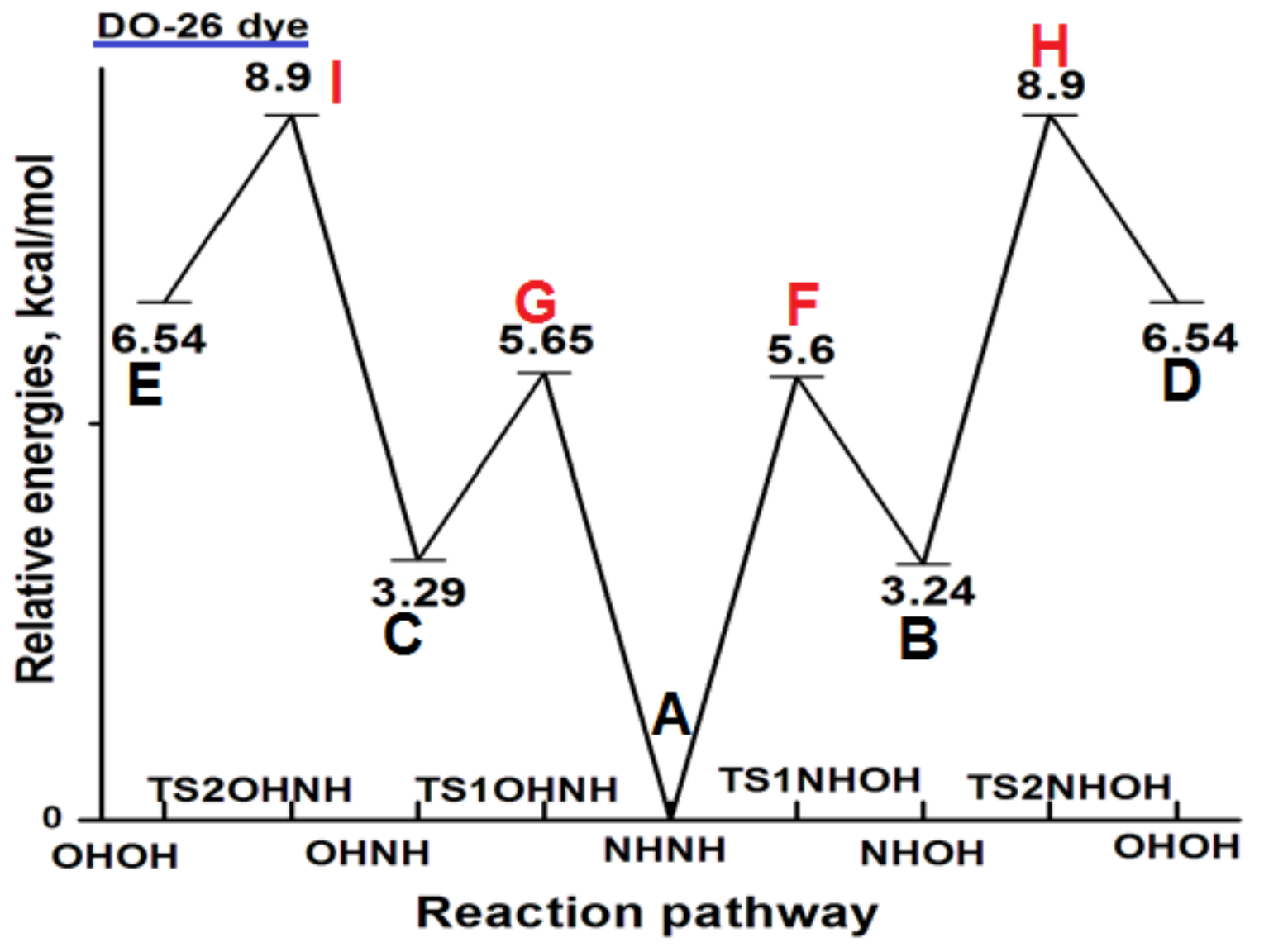

Figure 4 
Potential relative energy surface for the different tautomeric forms transformations of D0-26 dye (D1) calculated at the B3LYP/ 6-311++G(d,p) level of the DFT theory.

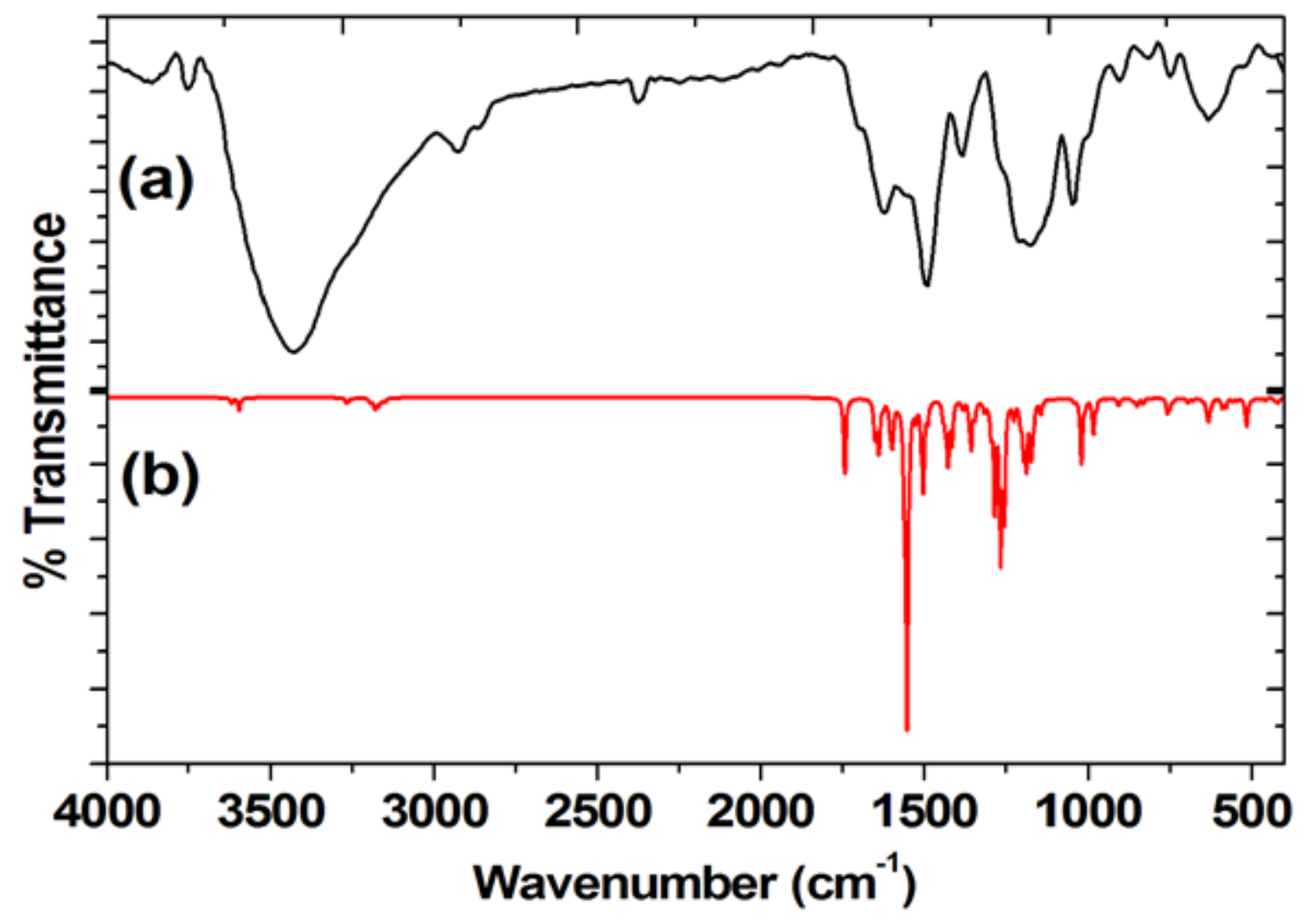

Figure 5

(a) Experimental FTIR and (b) simulated IR spectra in the region 4000-400 cm-1 of the D0-26 dye (D1).

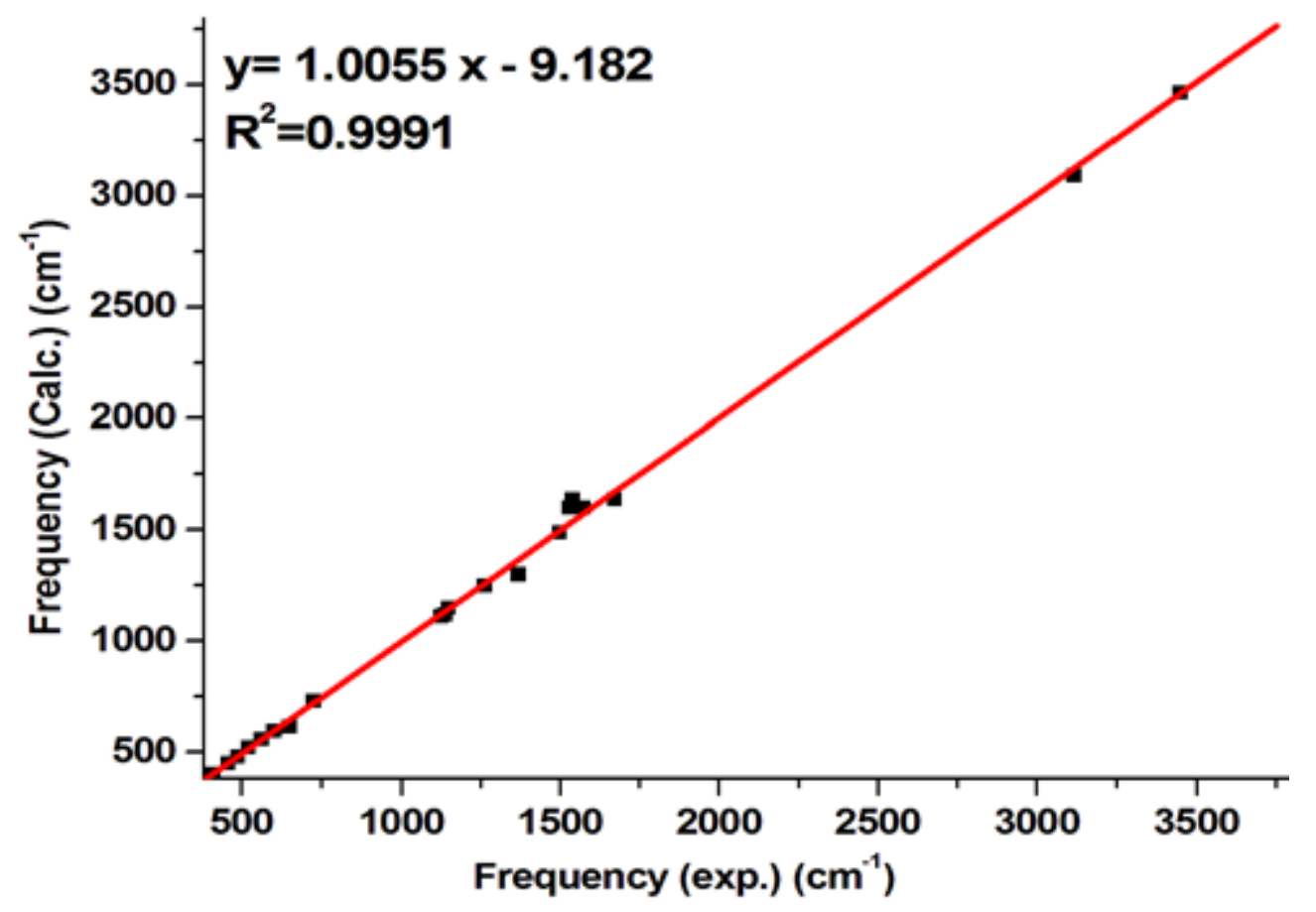

Figure 6 
Correlation between experimental FTIR and simulated IR spectra in the region $4000-400 \mathrm{~cm}-1$ of the D0-26 dye (D1).

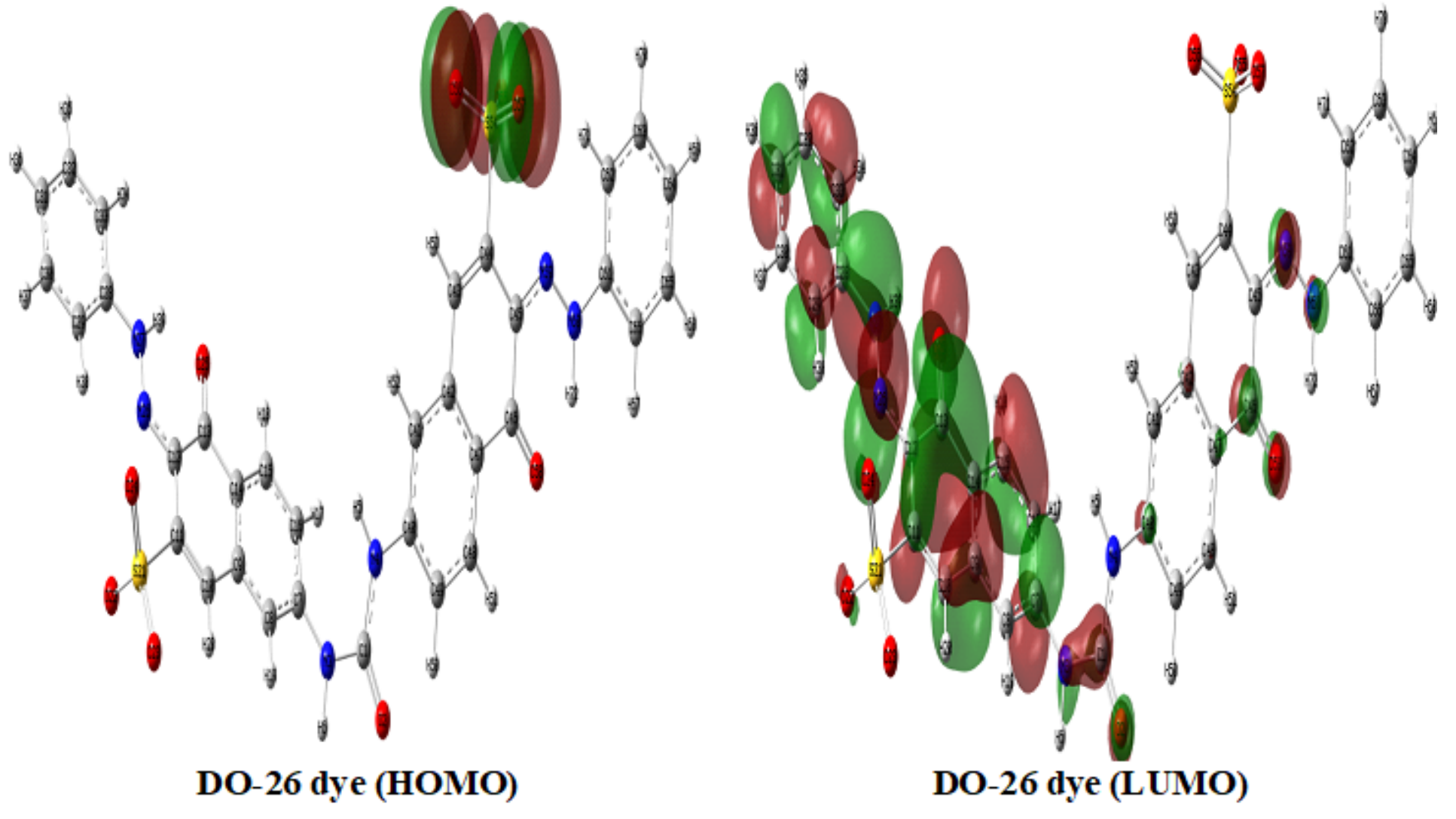

Figure 7

Frontier molecular orbitals of the synthesized D0-26 dye compound (D1)

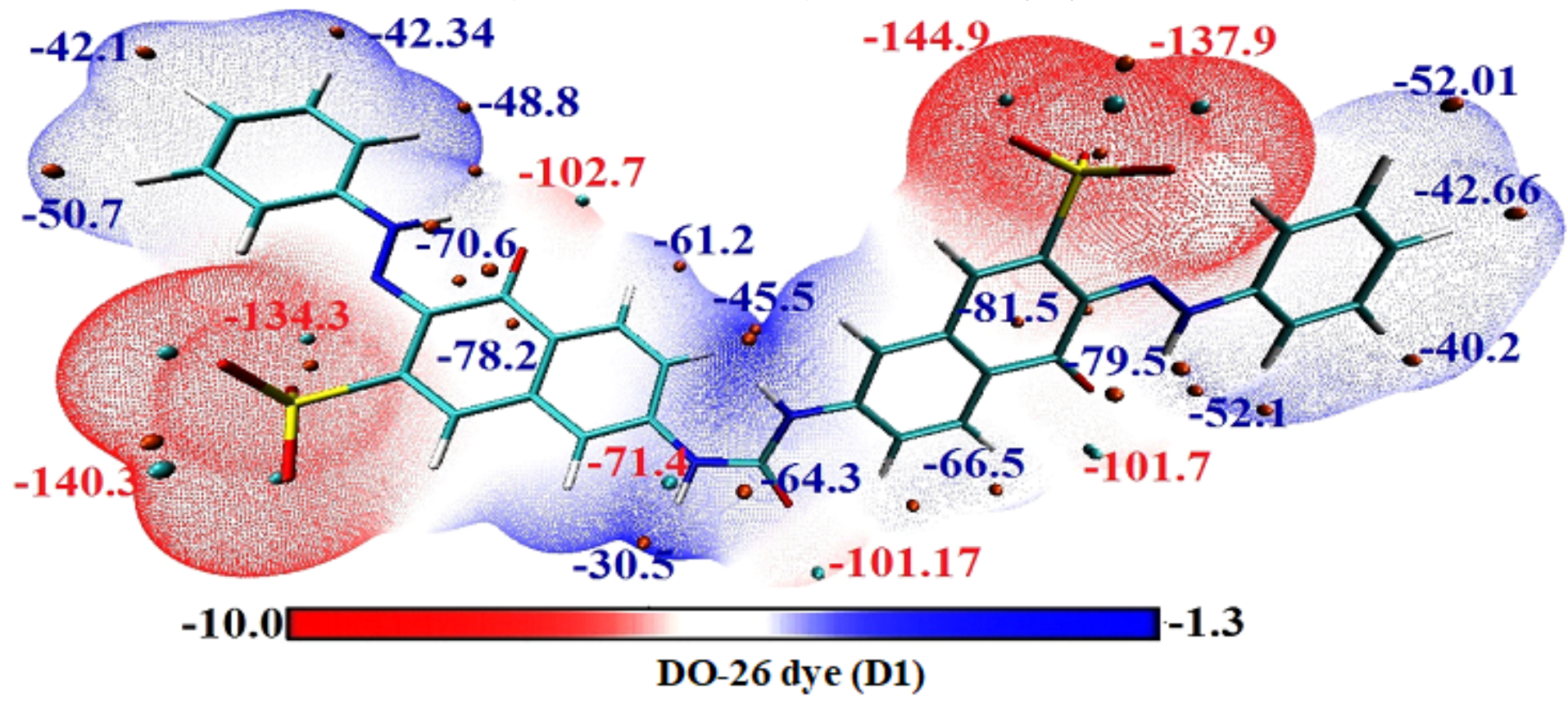

Figure 8 
MEP surfaces of the synthesized DO-26 dye compound (D1)

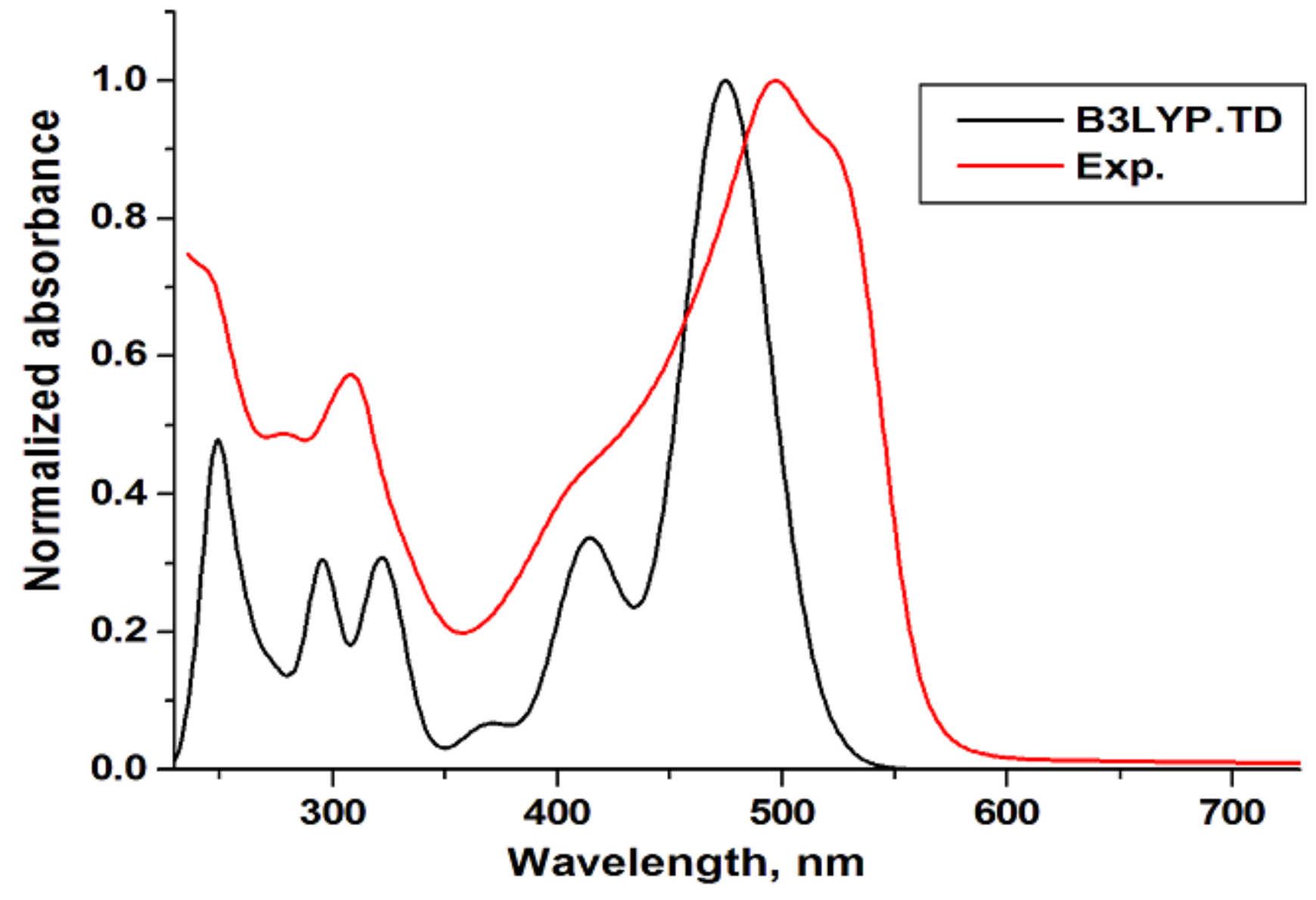

Figure 9

Experimental UV/Visible spectra of D026 dye (D1) and theoretical spectra obtained at the TD-PCM-B3LYP (Water) /6-311++G(d,p) level of approximation. 


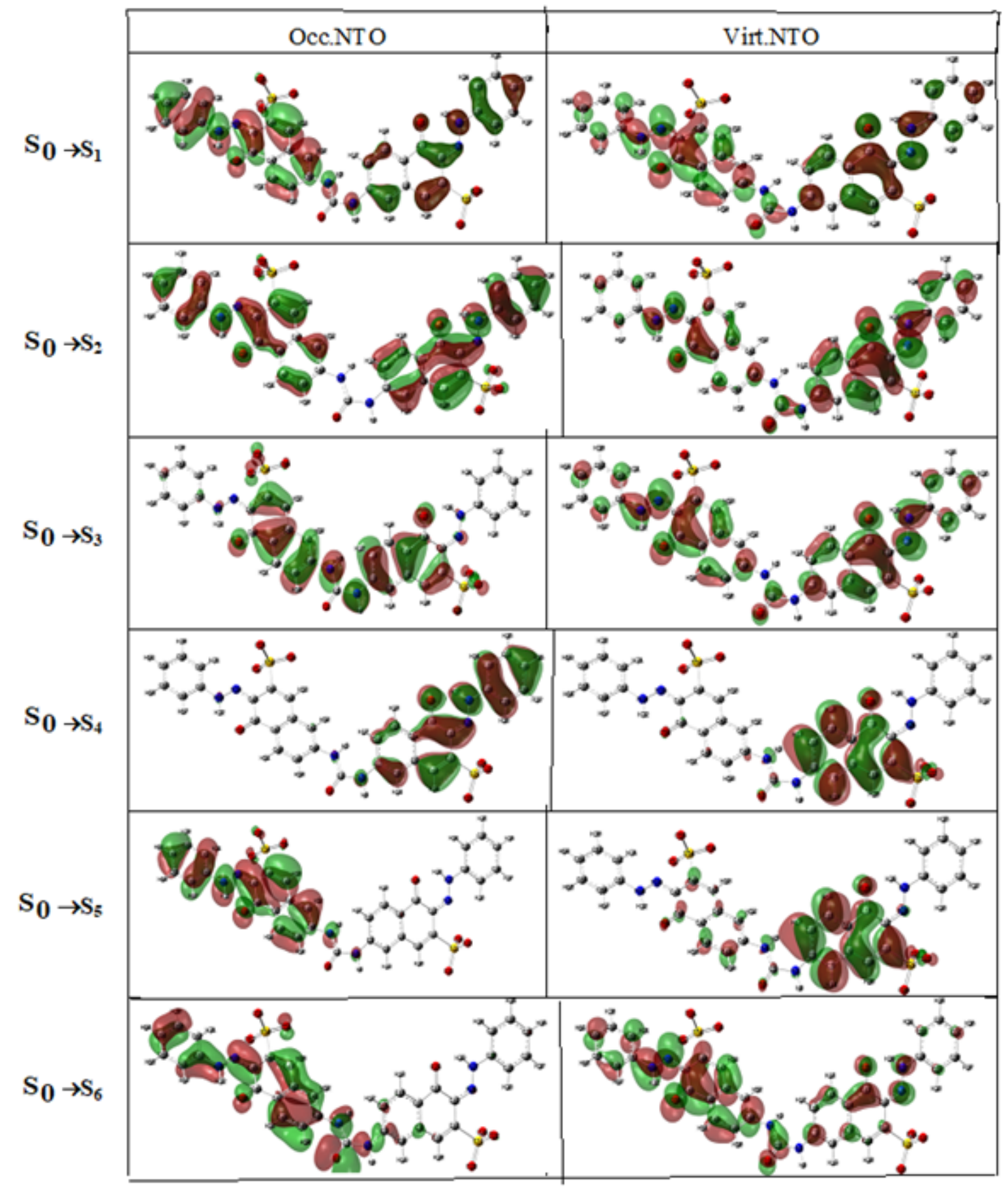

Figure 10

Natural transition orbitals (NTOs) occupied and unoccupied in the electronic transitions between the ground state (S0) and six low-lying singlet excited states (Sn) of D026 dye (D1) obtained at the PCMB3LYP (Water) /6-311++G(d,p) level of approximation.

\section{Supplementary Files}

This is a list of supplementary files associated with this preprint. Click to download. 
- Graphicalabstract.docx

- MSD026supplementary.docx 